\title{
EL PROBLEMA PESQUERO CON LOS DELFINES Y SU PERSECUCIÓN EN GALICIA (SIGLOS XIII AL XX)
}

\author{
FELIPE VALDÉS HANSEN*
}

\begin{abstract}
Resumen
Se realiza un estudio histórico sobre la problemática interacción entre el hombre como pescador y los delfínidos en Galicia, con la consiguiente persecución de los cetáceos, a los cuales culpan de la escasez de pescado, como depredadores y ahuyentadores de los bancos de peces lejos de la costa, además de ocasionar destrozos en las redes. Se presta especial atención a los aspectos más peculiares de su persecución, como la legislación, los consejos del ilustrado fray Martín Sarmiento, las corridas de arroaces en Pontevedra o las batidas por parte de las patrulleras de la Armada dentro de las rías. Finalmente, tras haber aludido a las primeras tentativas de industrialización de las manadas de delfines desde el siglo XVIII, se analiza el proyecto más destacado en el siglo XX, intentando involucrar en el negocio a la industria ballenera gallega. Todo ello sin obviar lo que acontece en el resto de España por su relación directa, como precedente del caso gallego o a modo comparativo.
\end{abstract}

\section{Palabras Clave}

Delfines, pesca, Galicia, siglos XIII-XX.

\begin{abstract}
An historical study is undertaken to show the conflictive interaction between man as a fisher and dolphins in Galicia, which results in a chase of cetaceans, held responsible as predators for the driving away of fish schools from the coastal waters and for the damaging of fishermen's nets. Special attention is given to the most peculiar aspects of this chase, such as its legislation, the massive killing of dolphins in Pontevedra, or the chasing runs by navy patrolboats in the river estuaries of Galicia. Finally, after mentioning the attempts at establishing a dolphin industry in the $18^{\text {th }}$ and $19^{\text {th }}$ centuries, a study is made of the most ambitious plan undertaken in the $20^{\text {th }}$ century to secure the involvement of the whaling industry into this activity. The study also refers to the situation of this activity in the rest of Spain both for its direct relationship with and as a precedent for the Galician case, and makes a comparison between them.
\end{abstract}

\section{Key Words}

Dolphins, fisheries, Galicia, $13^{\text {th }}-20^{\text {th }}$ centuries.

* Instituto de Estudios Gallegos «Padre Sarmiento», Consejo Superior de Investigaciones Científicas (CSIC)-Xunta de Galicia. 


\section{INTRODUCCIÓN}

Podrá sorprender a no pocos el tema objeto de estudio del presente artículo. Cabe preguntarse, ¿es realmente importante ocuparnos de una actividad pesquera ocasional y sin aparente repercusión económica? Porque, efectivamente, no la tuvo como actividad estable y con proyección comercial más allá de lo local, aunque no fueron pocos y fracasados los intentos por conseguirlo. La importancia del hecho radica en la interacción entre este cetáceo y el hombre como pescador, pues durante muchos siglos fue considerado un competidor directo que esquilmaba los bancos de peces y dañaba las redes - esto sí con fundamento- al comerse el pescado enmallado. No es de extrañar por esta razón la animadversión al delfín entre las gentes de mar que, hasta hace poco tiempo, estaba tan arraigada que incluso en el plano cultural dio pie a refranes y festejos populares como las corridas de arroaces de la ría de Pontevedra. Así pues, en lo económico la importancia no radicaba en el beneficio directo que se podía obtener con la venta de su carne y aceite, ni en el hipotético e improbable aumento de las capturas de pescado que conllevaría su desaparición, sino en la disminución de un perjuicio económico al evitar la rotura de los aparejos y la consiguiente reducción del esfuerzo pesquero que ello representaba, al interrumpir el normal desarrollo de las faenas pesqueras (forzosa vuelta a tierra para reparar las redes).

En cambio, no debe sorprender que a lo largo del artículo superemos, en no pocas veces, la demarcación geográfica gallega pues todo estudio local que se precie requiere de la comparación con lo que acontece en otros lugares para, de este modo, encontrar precisamente la peculiaridad de lo local. Ello nos permitirá comprobar que la interacción pesquera y persecución de los delfínidos fue generalizada en toda la costa española pero en Galicia no sólo fue así, sino que en ningún otro lugar como éste alcanzó tanta notoriedad, ni se desplegaron métodos de pesca parecidos. La razón de ello la encontramos en la singular conformación geográfica del litoral gallego con sus amplias y abundantes rías, que incrementaban el grado de interacción entre las manadas de delfines y la intensa actividad pesquera que dentro de estas rías - hoy reconvertidas al cultivo del mejillón a falta de aquella riqueza piscícola- desarrollaban los pescadores. Además nos parece absurdo obviar lo imbricado de la historia de las diferentes regiones que conforman España, como tendremos ocasión de comprobar a propósito de las reclamaciones que en Cantabria suscitaba la persecución de los arroaces en la ría de Vigo, los intentos desde Cataluña por fomentar una industria del delfín en colaboración con la industria ballenera gallega, aparte de ocuparnos de la inevitable legislación común a todo el país, etc. 
Y por último, en cuanto al amplio espacio cronológico elegido, si las peculiaridades subyacen en la no estanqueidad del estudio en lo geográfico, en este caso hemos optado por no ceñirnos a un período histórico en particular (p.e. Edad Moderna o Contemporánea) siendo éste un estudio que pretende evidenciar las etapas o cambios en la interacción de un problema pesquero, que precisamente sólo se manifiestan a través de la larga duración (como son la introducción de las grandes artes de pesca en el s. XVI, los impulsos revitalizadores de las pesquerías en la segunda mitad del s. XVIII a cargo de los ilustrados, el incremento de la pesca de altura en detrimento de la de bajura en el s. XX, etc.). Y no sólo eso, porque ¿cómo entender los problemas que las manadas de arroaces ocasionaban a los pescadores en los siglos XVII o XVIII, si ignoramos unas fuentes contemporáneas mucho más explícitas sobre un problema que, en esencia, seguía siendo el mismo? o ¿cómo ocuparnos de las corridas de arroaces en Pontevedra en el siglo XIX, sin antes haber estudiado los precedentes con las recomendaciones del Padre Sarmiento el siglo anterior? y viceversa, etc.

\section{LA PESCA DE DELFINES EN LA EDAD MEDIA Y EDAD MODERNA}

- Primeros datos de captura en Galicia. - Animadversión en el Cantábrico. - Primer intento de industrialización en la ría de Arousa. - La recomendación del Padre Sarmiento en Pontevedra como precedente de las corridas de arroaces. - Las corridas de arroaces en la ría de Pontevedra.

La pesca del arroaz -también llamado delfín mular-y otros delfínidos, además de la marsopa, fue antaño una tradición muy arraigada en Galicia y el Cantábrico. Documentalmente dicha actividad pesquera se remonta al medievo y comprendió dos etapas en lo referente a los medios técnicos y métodos empleados para tal fin: en primer lugar la pesca tradicional hasta el siglo XIX caracterizada por el uso de aparejos (redes) y pertrechos (arpones) artesanales, la cual precedió a la etapa moderna durante el siglo XX con la proliferación de las armas de fuego a bordo de las embarcaciones pesqueras, aunque usos y costumbres se solaparon en el tiempo.

Es el delfín mular (Tursiops truncatus) de acusado instinto costero y fue, por esta razón, la especie que mayores problemas ocasionó a la actividad pesquera y, por tanto, la más perseguida. Además de este delfín -que todos hemos visto alguna vez cerca de las playas, en la televisión o en los delfinarios- los otros pequeños cetáceos que fueron objeto de persecución cuando se aproximaban a la costa fue-

Cuadernos de Estudios Gallegos, Tomo LI, Fascículo 117, Santiago 2004. (Págs. 313 - 362) 
ron el delfín común (Delphinus delphis) y la marsopa (Phocoena phocoena). Ocasionalmente se debieron pescar -aunque no tenemos constancia documental de ello- otras especies de delfínidos de hábitos menos costeros como el delfín listado, el calderón, el delfín gris y quizás la orca.

Tempranamente, en el siglo XIII, ya encontramos a las touinas en los fueros municipales de Padrón en lo concerniente al pago del portazgo que recaía sobre los diferentes pescados:

«e del barquo de los congros, quer sean muchos, quer pocos, ha de aver el mayordomo un congro. Et se fuere otro pescado grande que sean yuos o touinas o prasos, o otros peces grandes anse de avenir con el mayordomo sobre ello» ${ }^{1}$.

Se trata del delfín común y no, como cabría pensar por una cuestión de similitud lingüística, de la marsopa que en el actual gallego normativo recibe el nombre de toniña, pues todavía en no pocos lugares de Galicia el delfín común es conocido entre los pescadores como touliña, toliña, tolina o tolino y no con el nombre específico de golfiño, que han impuesto en el gallego actual en detrimento de estas otras denominaciones. También conviene matizar que esta touliña es tanto el delfín común como el menos frecuente delfín listado -ambas especies muy parecidas en su morfología-, lo cual no significa que los marineros no supiesen distinguir entre una y otra, cuyo diferente colorido de la piel en los costados conocían, mientras que el mular o arroaz era también llamado golfiño. Con lo cual tenemos servida cierta confusión en los actuales nombres del gallego normativo para referirse a los pequeños cetáceos. Por un lado, las touliñas, tolinos, etc. (delfines común y listado) de los marineros que en el gallego actual serían sólo los golfiños, mientras que no hay contradicción al denominar el delfín mular como arroás o arroaz, si bien desacertadamente en el gallego normativo se ha obviado que también era llamado golfin o golfiño, un término éste que podemos considerar tan genérico como el de delfin para aludir a todos los pequeños cetáceos costeros (touliñas, arroaces y marsopas). Y ciertamente, las actuales denominaciones de golfiño común y golfiño riscado para referirse al delfín común y listado del castellano, que en realidad son las touliñas de los pescadores gallegos (también llamadas de forma menos específica, como el resto de pequeños cetáceos, golfins o delfins), nos parecen poco acertadas.

${ }^{1}$ LÓPEZ FERREIRO, A.: Fueros municipales de Santiago y su tierra, 1975 (1875), p. 507. 
Una antigua denominación la de tolino, touina, touliña o tolina, si nos atenemos a la afirmación de Enrique de Villena que, en su célebre tratado de gastronomía medieval (el Arte Cisoria del s. XV), alude a un nombre parecido, el tohoyno, para referirse al dalfin:

«el pez mular -es decir, el actual delfín mular o arroaz-e sobrayo se tajan asy menudo, que son grandes e duros pescados, e traydos en pieças. Eso mesmo fazen del dalfin a que llaman en estas partes tohoyno. E de los otros pescados, otro tal, que fueren bestinales e duros»².

Vemos también como todavía se establece cierta diferencia entre el pez mular -hoy delfín mular-y los delfines, como el tohoyno, pues todavía en el XVIII no estaba muy claro que este pez mular perteneciese a la misma familia de los delfines tal como lo afirmaron Sarmiento («aún no sé si es delfin el arroaz») y Cornide («hasta ahora no está bien averiguado que este pez sea el delfin de los antiguos») ${ }^{3}$.

En cuanto a las tounias de Padrón se entiende que se trataría de cetáceos capturados en la ría de Arousa u otras cercanas y luego vendidos en Padrón, pues no remontaban los delfines el río Ulla hasta tal extremo. Algo más al norte, a principios del siglo XVII, parecen relativamente comunes las capturas de delfines en las inmediaciones del puerto coruñés de la Pescadería, si nos atenemos a la información del cardenal compostelano Jerónimo del Hoyo quien afirma que «en este puerto se ven muchas diferencias de pescados como son cesial, congrio, besugos, atunes, delfines ${ }^{4}$.

Por tanto, se consideraba a los pequeños cetáceos entre los peces grandes junto a congrios, atunes, besugos y otros. De las noticias de Padrón (lo que debía adeudar la carne de este cetáceo al entrar en la ciudad con el resto del pescado), de Enrique de Villena (como se cortaba la carne) y del puerto de la Pescadería (principal punto de venta de pescado en A Coruña), se deduce una captura con fines claramente alimenticios. Pero desde el siglo XVII, tras el incremento de la actividad pesquera y el uso de las grandes artes de pesca se percibe en las fuentes documentales un odio, cada vez mayor y generalizado, hacia el delfín. Nos encontramos ahora ante un aumento del consumo del pescado y el uso de redes de mayor

\footnotetext{
${ }^{2}$ VILLENA, E.: Arte Cisoria, Editorial Humanitas, Barcelona, 1984, p. 107.

${ }^{3}$ CORNIDE, J.: Ensayo de una historia de los peces y otras producciones marinas de la costa de Galicia, Edicións do Castro, 1983 (1787), p. 108.

${ }^{4}$ HOYO, J. del: Memorias del arzobispado de Santiago, Santiago de Compostela, 1950 (1607), p. 224.
} 
tamaño como los cercos calados durante días ${ }^{5}$, además de la expansión de jeitos y trasmallos donde los delfines se comían los peces enmallados con el consiguiente destrozo de la red. Desde entonces las noticias documentales o bibliográficas cambian de sesgo y ponen de manifiesto una captura en la que la venta o consumo de la carne es absolutamente secundario, porque de lo que se trata ahora es de exterminarlo o ahuyentarlo con el propósito de evitar los perjuicios que causaban: daños en el aparejo y escasez del pescado que supuestamente esquilman o alejan de la costa.

Sobre la ojeriza que empieza a despertar este cetáceo es bien significativo la leyenda del siglo XVII sobre el pleito de los delfines y la curiosa escritura sobre el conjuro de los calderones en Asturias, de lo cual nos ocupamos brevemente como ilustrativo ejemplo de la enraizada animadversión del pescador por estos mamíferos marinos en el litoral cantábrico, ya sea el gallego o asturiano, como en este caso. Poca o ninguna credibilidad cabe otorgar al cronista Gil González Dávila que en su Teatro Eclesiástico de la Santa Iglesia de Oviedo (1635) alude a dicho pleito entre los pescadores de varios puertos de la costa asturiana - con el cura de Candás al frente- y los cetáceos -a los que incluso se impuso un abogado defensor-culpables de destrozar sus aparejos de pesca, razón por la que finalmente fueron condenados leyéndose la sentencia en alta mar. Poco importa si se trata, como todo parece indicar, de una leyenda o cabe considerarlo como un suceso realmente insólito porque, ante todo, se trata de la temprana manifestación del conflicto pesquero que aquí nos ocupa y de la condición del delfín como chivo expiatorio de los problemas pesqueros. Al igual que el conjuro de los calderones, en este caso verídico, del que tenemos noticia por una escritura fechada el 8 de septiembre de 1624 en la que se da cuenta del problema:

\footnotetext{
${ }^{5}$ Según el Padre Sarmiento había en Pontevedra en el siglo XVII «12 cercos que costeaban y utilizaban los mareantes de aquella villa, y en el espacio del tiempo apto para echar los cercos, que era desde el día después de San Bartolomé hasta acabar el año, se cogían por lo regular 130 millones de sardinas. Y porque pocos hacen idea de lo que es un millón, digo, para que todos la hagan, digo en grueso, que si estos 130 millones se hubiesen de portear en machos de maragatos, cargando cada uno con 12 arrobas de sardinas, eran precisos 32.000 machos para portearlas todas; y haciendo una sola fila o recua de tantos machos, aun yendo tan juntos unos con otros que se alternasen cola con cabeza y cabeza con cola, tendría de largo esa recua o fila 20 leguas de las comunes», en FERREIRA PRIEGUE, E.: «O desenvolvemento da actividade pesqueira desde a alta idade media ó século XVII», Historia da pesca en Galicia, USC, Santiago de Compostela, 1998 , p. 82.
}

Cuadernos de Estudios Gallegos, Tomo LI, Fascículo 117, Santiago 2004. (Págs. 313 - 362) 
«que por cuanto en la mar y comarca de esta villa los vecinos circunes de ella no pueden entrar en ella con sus pesquerías por los grandes daños que les acen los peçes bravos que llaman delfines dichos calderones, no solamente en las pesquerías sino a sus aparejos que de ordinario les açen notorios daños» ${ }^{6}$.

El documento en cuestión es el acuerdo suscrito entre los pescadores de Candás y los de Gijón para costear, a partes iguales, la contratación de un clérigo del Santo Oficio de la Inquisición del que se decía era capaz de ahuyentar a los animales salvajes y los peces dañinos (en este caso calderones). No debe sorprendernos encontrarnos a un clérigo del Santo Oficio ocupado en semejantes menesteres ya que por aquel tiempo los animales como el lobo, los roedores, delfines, etc., se consideraban plagas demoníacas con las que mortificar a los cristianos y, de paso, perjudicar las ganaderías, cosechas y pesquerías que tan buenos réditos proporcionaban a la Iglesia a través del diezmo.

Así pues, demonizados los delfínidos, de entre todas las especies fue el arroaz debido a sus hábitos marcadamente costeros la que en mayor medida interfirió con la pesca de bajura y más odio suscitó entre los pescadores. Por ello y por el hipotético beneficio que se podía obtener con la cocción de su grasa o consumo de la carne, hubo en Galicia alguna propuesta de industrializar su pesca en la segunda mitad del siglo XVIII en la ría de Arousa, según el ictiólogo coruñés José Cornide Saavedra:

«Los arroaces entran en nuestras rías siguiendo la sardina en grandes bandadas, $y$ caminando a saltos, con los que descubren fuera del agua casi todo el cuerpo, los temen mucho los pescadores porque les ahuyentan la pesca, y les rompen las redes; $y$ asi por esta razón, como por la utilidad que se pudiera sacar de su grasa, se debiera fomentar su pesca, como lo han propuesto unos comerciantes de la ría de Arosa»?.

En la ría de Pontevedra, después de muchos años sin utilizarse, el Ministro de Marina de Pontevedra Francisco Javier Sarmiento restableció el cerco en 1749 con el cual se pescaron 14 millones de sardinas durante tres meses, lo que equivalía económicamente a la mejor almadraba del Mediterráneo según Sáñez Reguart ${ }^{8}$. En

\footnotetext{
${ }^{6}$ BUSTO, M.: «Pudiera no ser fabuloso el pleito de los delfines. Esta basado en un hecho real y verdadero», Boletín del Instituto de Estudios Asturianos, n 102, Oviedo, 1981, pp. 367-372.

${ }^{7}$ CORNIDE, J.: Ensayo de una historia de los peces..., p. 109.

${ }^{8}$ SAÑEZ REGUART, Antonio: Diccionario histórico de los artes de la pesca nacional, Ministerio de Agricultura, pesca y alimentación, Madrid, 1988 (1792), pp. 155-156.
} 
este contexto de recuperación de las pesquerías su hermano, el ilustrado fray Martín Sarmiento -que precisamente en 1749 ya le había ayudado escribiendo seis pliegos sobre el cerco de sardinas en Pontevedra9-, le recomendó la matanza sistemática de los arroaces al modo que luego se hará, aunque intuye el rechazo que su propuesta suscitaría inicialmente:

«Los arroaces andan en tropa y sacan fuera el cuerpo. Con cercar esa tropa con una red común y por fuera con un cerco de barcos, o al contrario, siempre vendrán a los barcos para escapar. Entonces con francadas, dardos, arpones, escopetas, lanzas, etc. se les puede acometer de seguro. Las redes podrán hacerse de juncos, de esparto, de mimbres, de gestas, etc. que cuesten poco y tengan las mallas muy anchas Pero reinando ahi la vulgaridad de que la sardina huye de la sangre del arroaz, es excusado pensar en arbitrio alguno. Creíble es que el celo y huevas sean por primavera. Entonces no hay sardina, ni pesca, y así no hay motivo para el temor.

Si ahi se rien de la batida diles que yo me río de sus quejas y me compadezco de las batidas que van a hacer de lobos a la Ponte-nova. Al modo que se pescan las ballenas se deben pescar los arroaces. Es cierto que el saín costearía el gasto y defendería la batida a la pobre sardina.

En uno, ni en cuatro, ni acaso en diez años, no se apurarían los arroaces, pero cada día irían a menos. Las redes exteriores de los atunes son flojas y de esparto.

Dirán que no sabrán armar. Pues que traigan uno de los que han ido a la pesca de las ballenas. ¿Y qué sé yo? Acaso vendrian a las redes algunos atunes y era otro tanto oro» ${ }^{10}$.

Los temores que el Padre Sarmiento manifestó en la correspondencia a su hermano sobre el rechazo o escepticismo de los moureiros eran fundamentados y la propuesta no fue bien recibida, puesto que existía la creencia que la sangre del arroaz ahuyentaba la sardina de la costa. No sólo la de éste, sino la de los cetáceos en general pues se trata de una creencia que también hemos podido documentar en los primeros años de la expansión de la actividad ballenera en el siglo XVI, cuando hubo una intensificación sin precedentes de esta otra pesca de cetáceos en la costa gallega ${ }^{11}$. Se enten-

${ }^{9}$ GARCÍA TATO, I. y VALDÉS HANSEN, F. (ed.): Vida y obra del Reverendo Padre Maestro Fray Martín Sarmiento (1695-1772), CSIC-Xunta de Galicia, Santiago de Compostela, 2003, p. 43, nota 4.

${ }^{10}$ FILGUEIRA VALVERDE, X. y FORTES ALÉN, M. X.: Fr. Martín Sarmiento. Epistolario, Consello da Cultura Galega, Santiago de Compostela, 1995, p. 64 (carta del 9-3-1757).

${ }^{11}$ Tesis doctoral inédita del autor. 
día que era peor el remedio que la enfermedad e incluso un vecino de Marín informó en 1759 al Padre Sarmiento que había realizado una red para tal cometido y que finalmente acabó Vilanova de Arousa, ante la negativa de los moureiros de emplearla para la matanza de arroaces:

«Dijo que habia tentado hacer unas redes a tender, en la Barca, desde San Pedro de Finz hasta la Moureira para pescar, los arroaces, pero que, aburrido de que los moureiros se habian opuesto, había remitido dichas redes a Vilanova da Arousa, ni sé a quién, para que las utilizase.

Con esta ocasión le dije lo de cegar los arroaces en Mayo y en Junio etc. No lo habia oído. Se alegró mucho y va en ánimo de no echar en olvido la observación, y le dije que en caso de ceguera, podría echar las redes en alguna ensenada y moler a palos los arroaces a docenas» $»^{12}$.

El método de la red era una manera de intervenir en lo que hasta entonces era una costumbre ancestral como es el aprovechamiento de la carne y la grasa de los cetáceos varados en los arenales, pero ahora forzando este accidente natural en la vida de los delfines con el propósito de exterminarlos. Y en cuanto a lo de la ceguera, Sarmiento se fundamenta en ciertas lecturas científicas -todavía comprensiblemente desatinadas en algunos asuntos- que aseguraban que los delfines sufrían una pérdida de visión transitoria durante el mes de junio, momento propicio para acorralarlos y matarlos ${ }^{13}$. El Padre Sarmiento, inmerso en su propósito, sigue recabando información para su hermano contando con algún testimonio que nos remite a las primeras matanzas documentadas de arroaces en la ría de Pontevedra, con ocasión del varamiento de una manada de doce ejemplares antes de 1758, reafirmando su convicción de persuadir a los pescos para llevar a cabo tal empresa:

«Hablándole de la ceguera de los arroaces, dijo que él habia visto doce arroaces juntos que habian entrado en la boca de aquel riachuelo de Goyanes que desagua en la lengua de agua de la casa de los Camaños. Que alli habian quedado, al bajar el mar, casi en seco y que a todos doce los mataron alli a palos y los utilizaron. Él ha sido testigo de vista.

Agrega este hecho al de venir al puente da Boa Vila arroaces y los dos a la ceguera de - los arroaces en junio y julio, y mi conjetura, si entonces, como los atunes, tiene mosca

${ }^{12}$ FILGUEIRA VAlVERDE, X. y FORTES ALÉN, M. X.: Fr. Martín Sarmiento..., p. 152 (carta del 13-6-1759).

${ }^{13}$ Ibidem, pp. 102-103 (carta del 11-4-1758). Véase apéndice. 
marina que los hace rabiar y andar como perros tontos. Al modo que como tales se metieron los 12 en la lengua de agua de Goyanes se podría amañar que andando ciegos, se les hiciese entrar en una ensenadita y matarlos alli a poca costa. Ya ves que perfecto éste para los pescadores, si se entablase. Asi muele y remuele a esos marineros para que hagan la observación sobre los arroaces.

Supongo dirán, non señore, acá non facemos eso» ${ }^{14}$.

Insistentemente, desde su celda del monasterio de San Martín de Madrid, el Padre Sarmiento incoaba a su hermano para que verificase lo cierto o infundado de la ceguera de los arroaces en el mes de junio, dada la importancia del hecho de cara a su persecución:

"Con la observación de que los arroaces andan ciegos en mayo y junio propuse que si ahi se les observaba esa ceguera era fácil cogerlos a palos y a docenas. Avisete que esparcieses la voz para la observación y no tuve respuesta. Repito la instancia para que propongas a los pescos que cuando por junio vieren bandada de arroaces se observe si flotan como ciegos o perros tontos. ¿Qué les costará esto?» ${ }^{15}$.

La creencia de la ceguera no debe ser tomado como una ingenuidad científica de la época, ya que era una posible explicación a los varamientos de las manadas de cetáceos que, todavía hoy, se envuelven en un halo de cierto misterio. Además se alude a un parásito - la mosca marina-como causa de esta anormalidad en su conducta, lo cual en la actualidad -nos referimos a ciertos parásitos internos que podrían motivar una desorientación- es una hipótesis de trabajo muy extendida entre los biólogos como una de las causas de los varamientos de cetáceos vivos ${ }^{16}$.

No sabemos cuánto tiempo tardó en implantarse esta costumbre pero lo cierto es que, a lo largo del siglo XIX, se hicieron muy populares en Pontevedra las corridas de arroaces durante las fiestas de la Peregrina. En el transcurso de los festejos, el día señalado aprovechando la pleamar, los pescadores acosaban las manadas de arroaces remontando la ría y a la altura del barrio pesquero de la Moureira -en la orilla de las Corbaceiras- extendían una red de esparto hasta la otra orilla -la de Poio-, cortando la retirada de los cetáceos en su vuelta al mar. Una vez allí eran acosados y arponeados -cuando no tiroteados y apedreados- por

${ }^{14}$ Ibidem, p. 108 (carta del 31-5-1758)

${ }^{15}$ Ibidem, p. 139 (carta del 25-4-1759) y pp. 106-107 (carta del 24-5-1758).

${ }^{16}$ VV.AA.: Ballenas, delfines y marsopas, Plaza \& Janes-Tusquets, Barcelona, 1991, p. 216. 
los moureiros, alentados desde la orilla por los lugareños y forasteros que acudían a presenciar el festejo. Así lo atestigua en un largo poema (véase íntegro en el apéndice) el poeta local José Benito Amado, al cual citamos teniendo en cuenta que dichos versos, compuestos como oda de los festejos populares de Pontevedra y su gente, se convirtieron en la fuente de la que se sirvieron las descripciones posteriores que, sin embargo, han omitido la procedencia de la información. Es la razón por la que las descripciones posteriores por parte de autores que no conocieron el festejo suelen incurrir con facilidad en la connotación aguerrida o heroica de la lucha entre hombre y cetáceo, no siendo así en el caso de algún autor que, como Cuveiro Piñol, fue testigo directo de lo relatado. Y es que su descripción nos recuerda más a las crueles escenas que todavía se repiten hoy en algunos lugares como Japón o las islas Feroe que a una modesta evocación de la pesca de la ballena: los moureiros esperaban la bajamar para acometerlos limitando la agilidad de la manada de delfines que, con apenas agua para nadar y menos para zafarse de los pescadores, heridos o muertos varaban y eran arrastrados -incluso por los niñoshasta la orilla. Comparemos brevemente una y otra:

José Benito Amado:«Al pasar, de una orilla a la otra la red se tiende, el paso atrás les veda, y crecen la ansiedad y la algazara sonando cien bocinas y trompetas. Al conocer el pez con raro instinto la celada y peligros que le cercan, más espantado y rápido se agita para huir de aquel ruido que le aterra. Seguro el cerco, ya el combate rudo y la corrida estrepitosa empieza. Erizadas de arpones las chalupas a los delfines rápidas se acercan y la lucha se traba, los aceros la carne dura del delfin penetran, $y$ enfurecido el monstruo se revuelve arrollando a su paso cuanto encuentra. Asi en juegos diversos y vistosos Pasan el tiempo mientras que en el mar mengua y convertido en un sangriento lago el sitio queda de tan rara pesca» ${ }^{17}$.
Juan Cuveiro Piñol: «Os animaes cando baixan do rio e alcontranse encerrados e ven que se lles vai acabando a auga do mar, comezan a dar unhas carreiras que se asemellan á voaduras, unhas veces emparellados e outras sôos; volvense tolos, é algún d'eles querse choutar â terra. Os homes e os rapaces, cando xa non queda d'auga mais q'a do rio, bótanse a él, póndose acabalo dos peixes, que c'o a mesma coraxe que teñen lévanos unha grande distancia sin cairse; outros tiranlles arpons, pedras é hastra tiros, de sorte que aquelo convírtese nunha festa d'un genero novo, d'a que non quedan pouco ademirados hastra os mesmos estrangeiros. Outras veces arremoiñanse en runfladas os arrôaces e acometen a rede, tal é o instinto que teñen, pro como está pol a parte de fora arrodeada de lanchas é botes, desd' elas con remos é paus, fan recuar ôs animaes, que xa fatigosos e cheos de firidas e pancadas, deixanse coller hastra dos nenos, e traenos â terra onde os poñen en toradas pra estraelles a graxa ${ }^{18}$.

${ }^{17}$ La Perseverancia, año I, $\mathrm{n}^{\circ} 46,13$ agosto 1859 . Véase apéndice.

${ }^{18}$ CUVEIRO PIÑOL, J.: «Unha corrida d'arroaces», $A$ Monteira, año II, $\mathrm{n}^{\circ}$ 25, 22 marzo de 1890, pp. 193-194. Véase apéndice. 
Con el tiempo fue desapareciendo esta costumbre como consecuencia de la regresión de los arroaces en aquella y otras rías. Prueba de ello es que el 13 de agosto de 1859 no se pudo celebrar el tradicional acontecimiento por no hallarse ninguna manada en toda la ría de Pontevedra:

«No hubo en cambio la corrida y pesca de golfines, que vale tanto como decir, primero que estos animaluchos no se dignaron realizar los deseos de la cofradía, segundo, que es mucho más fácil prometer que hacer» ${ }^{19}$.

La red, muy deteriorada, se conservó hasta finales del siglo XIX en un almacén de la Moureira, antes de que un incendio la destruyese. Ya entonces, según Prudencio Landín, habían desaparecido estas matanzas "porque delfines apenas asomaban en cantidad suficiente a la ría y, sobre todo, porque los pescadores no se mostraban muy propicios a repetirlo» ${ }^{20}$. Vemos pues, que el origen de estas matanzas está estrechamente vinculado al problema pesquero que aquí nos ocupa tras el restablecimiento del cerco y por ello, además del carácter lúdico (se celebraban en agosto coincidiendo con la festividad de la Peregrina), tenían una finalidad económica muy clara como era la reducción sistemática de las manadas de arroaces (además del aprovechamiento local de la grasa para el mantenimiento de la red y otros costos). De este modo se eliminaba a un competidor indeseable, al tiempo que se minimizaban los daños que en las redes de los pescadores pontevedreses provocaban los arroaces.

En cuanto a los arpones cabe señalar que no son raros los que todavía se conservan en algunas localidades costeras, como personalmente hemos podido comprobar, siendo confundidos con frecuencia con aquellos otros -más antiguos y bien diferentes- empleados en Galicia y el Cantábrico para la pesca de los grandes cetáceos como la ballena franca. Rodríguez Santamaría estimó en ¡más de quinientos! los que había en todo el litoral cantábrico a principios del siglo $\mathrm{XX}^{21}$. Los había de muy diferentes tipos aunque respondían a un mismo patrón: un hierro con una acanaladura u oquedad en la base para enhiestar el asta de madera, acabado en punta simple de doble filo o articulada, la cual adoptaba una posición transversal

\footnotetext{
${ }^{19}$ La Perseverancia, año I, no 47,18 agosto 1859.

${ }^{20}$ LANDÍN TOBIO, P.: De mi viejo carnet. Crónicas retrospectivas de Pontevedra y su provincia, Pontevedra, 1949, pp. 114-115.

${ }^{21}$ RODRÍGUEZ SANTAMARÍA, B.: Diccionario ilustrado, descriptivo, valorado, numérico y estadístico de los artes, aparejos e instrumentos que se usan para la pesca marítima en las costas del Norte y Noroeste de España, Madrid, 1996 (1911), p. 164.
} 


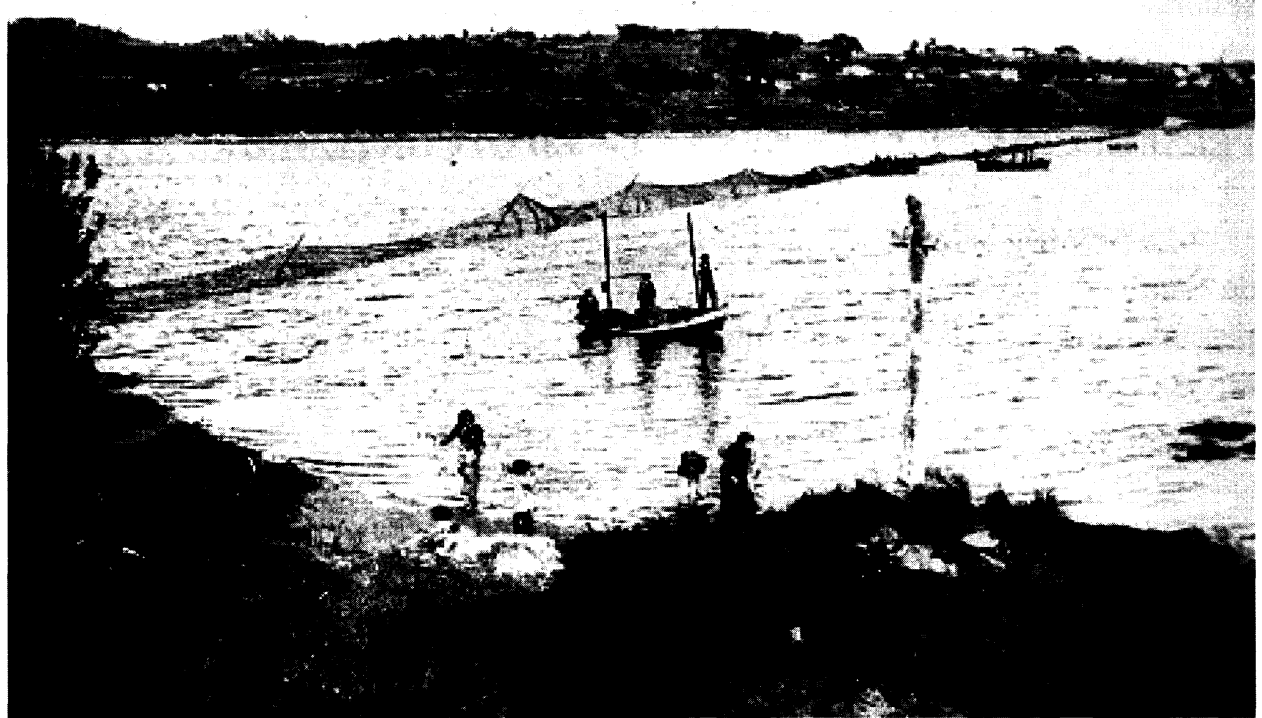

Red de pesca cerrando una ría gallega, similar a la que se utilizaría en el siglo XIX para realizar las corridas de arroaces en Pontevedra. Galicia: $O$ oficio de vivir. O Mar, p. 33.

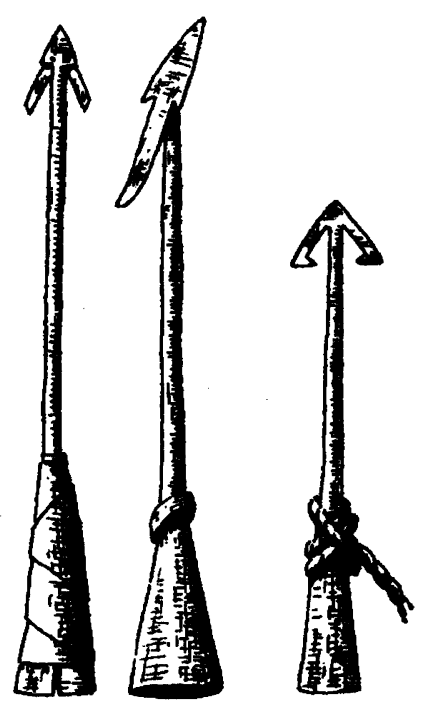

Ilustración de los arpones expuestos en el Museo de Pontevedra, utilizados en las corridas de arroaces. Los dos de la izquierda son de punta articulada. Historia de Galiza, vol. II, 1979, p. 413. 
respecto al astil del arpón dentro del cuerpo del cetáceo para impedir que se desprendiese con las sacudidas del animal, especialmente en el caso de tener que soportar los tirones de un cordaje o estacha.

\section{PERSECUCIÓN DE DELFINES EN LA EDAD CONTEMPORÁNEA}

- La propuesta de la Sociedad Económica de los Amigos del País de la Ciudad de Santiago para las rías de Arousa y Muros. - Legislación. - Protestas de los pescadores de las Rías Baixas e intervención de la Armada en la persecución de los arroaces. - Ineficacia del método y reclamaciones de los pósitos cántabros en relación con la persecución emprendida en las rías gallegas.

La Sociedad Económica Amigos del País de la Ciudad de Santiago, que como tantas otras surgió para tratar de poner fin al atraso económico del país, remitió en 1879 un estudio sobre este problema al Ministro de Marina, demandando la persecución de los delfines que supuestamente ocasionaban tanto perjuicio a las numerosas fábricas de salazón de las rías de Arousa y Muros, abastecidas con ingentes cantidades de sardina ${ }^{22}$. El dictamen de la comisión fue claro al no dudar en considerar «que la causa principal del estado de abatimiento y decadencia de la Industria de Salazón en aquellas rías, donde en otro tiempo se manifestaba tan rica y pujante, consiste, sin duda, en la imposibilidad de pescar la Sardina por los destrozos que ocasiona en las redes del jeito, un cetáceo voraz, conocido vulgarmente en nuestras costas con el nombre de arroaz, y que es el terror de los pescadores en aquellas comarcas $\rangle^{23}$. La comisión compuesta por José Antonio Parga y Sanjurjo, Antonio Llamas, Vicente González, Francisco Poch y Juan Goday, recomendaba la realización de batidas con armas de fuego en detrimento de los métodos tradicionales, aunque no se descartaba el uso de grandes redes con las que atrapar las manadas. Convenían igualmente que era necesario la presencia de tres lanchas de vapor tripuladas con tiradores para la ría de Arousa y otra más para la de Muros,

${ }^{22}$ PARGA SANJURJO, J.A. et al.: Informe a la Sociedad Económica de Amigos del País de la Ciudad de Santiago evacuado por la comisión de la misma Sociedad, encargada de estudiar y proponer el medio más conducente a evitar los perjuicios que a la Industria de la salazonera ocasionan los Delfines en las rías de Arosa y Muros, Gaceta de Galicia, Santiago de Compostela, 1879. Véase apéndice.

${ }^{23}$ Ibidem, pp. 3-4.

Cuadernos de Estudios Gallegos, Tomo LI, Fascículo 117, Santiago 2004. (Págs. 313 - 362) 
teniendo en cuenta la abundancia de cetáceos y extensión de cada una de ellas. En este contexto, reunidos en una asamblea en Vilagarcía todos los fomentadores y patrones de embarcaciones de la ría de Arousa y puertos cercanos, se acordó solicitar al Gobierno que dotase a los pescadores de «fusiles lanza arpones», lo cual nunca fue atendido ${ }^{24}$.

Y es que la legislación contemporánea sobre la protección de los delfines evidencia un claro desencuentro entre la Administración central y los pescadores o poderes locales (diputaciones y ayuntamientos). Si por parte de los gobiernos locales -más condicionados a las reivindicaciones de sus pescadores que el despersonalizado cuerpo de la Administración estatal- las medidas fomentaban su persecución y exterminio sin cortapisas, por el contrario, las Reales órdenes del Gobierno se encaminaban hacia su conservación apelando a la gran ayuda que para los pescadores representaban, como involuntarios delatores de la presencia de los bancos de peces. Una Real orden del año 1905 prohibía su persecución en base a ello y un año después a los pescadores de Vizcaya se les negó la autorización para llevar armas de fuego a bordo, con el fin de perseguir la marsopa (especie que el naturalista Ángel Cabrera consideró como muy abundante en el sur del Golfo de Vizcaya ${ }^{25}$ ), al tiempo que ese mismo año se desestimaba la petición del alcalde de Mataró sobre la necesidad de dictar disposiciones encaminadas a la extinción de los delfines ${ }^{26}$. En 1910 se prohíbe el uso de carabinas o arpones a los de San Sebastián y es que el uso del arpón en los arrastreros para matar los delfines con los que alimentarse a bordo era una práctica muy arraigada en toda la costa española y sobre todo entre los vascos. En 1913 se desestima la instancia de varios pescadores -no sabemos de dónde- que piden autorización para perseguir a los delfines con un barco dotado de tiradore ${ }^{27}$. En 1916 se considera que no procede modificar la legislación pesquera sobre la persecución de los delfines, dejándose sin efecto la decisión de la Diputación de Barcelona que premiaba con 500 pesetas a los primeros pescadores en matar doscientos delfines, mientras que en 1918 nuevamente fue necesario prohibir la utilización de armas en los pesqueros para tal fin ${ }^{28}$.

${ }^{24}$ BERNÁRDEZ, A.: «La pesca en Galicia», La Voz de Galicia, 18-7-1923, p. 1. Véase apéndice.

${ }^{25}$ CABRERA, A.: Fauna Ibérica. Mamíferos, Madrid, 1914.

${ }^{26}$ RODRÍGUEZ SANTAMARÍA, B.: Diccionario de las artes de pesca de España y sus posesiones, Madrid, 1923, p. 103.

${ }^{27}$ Ibidem.

${ }^{28}$ Ibidem. 
En esta aparente paradoja entre unos pescadores para los que el mejor delfín era sólo aquél que estaba bien muerto y una Administración que, ignorando dicha problemática, los protegía por considerarlos de gran utilidad para la pesca, hay que tener en cuenta que había unos pescadores más perjudicados que otros. Nos referimos a los que faenaban con trasmallos o jeitos en los que quedaban enmallados los peces que los delfines rapiñaban con el consiguiente destrozo de la red de algodón; mientras que los artes de cerco, como la traíña, no sólo no resultaban tan perjudicados (la red no quedaba durante horas a la deriva o fondeada), sino que además uno de los modos de pescar con la traíña era el mansío - del que hablaremos más adelante- echando el cerco en el lugar en el que los delfines se habían estado alimentando previamente de un banco de peces.

Tampoco hay que descartar que detrás de las negativas de las autoridades de la Restauración se escondiese el razonable recelo a que se extendiese el uso indiscriminado de las armas de fuego, sobre todo, en aquellas partes del litoral proclives al contrabando. Pero tocando a su fin el período de la Restauración se produce un cambio en este ámbito de la política pesquera y las reivindicaciones de los pescadores encontraron un mayor respaldo, una vez que se abordó el problema desde otra perspectiva. En 1923, a ruego de las asociaciones de pescadores de varios puertos del litoral gallego, se formó una comisión técnica compuesta por un capitán de la Dirección general de Navegación y Pesca, un doctor en Ciencias y Benigno Rodríguez Santamaría, del Instituto Español de Oceanografía ${ }^{29}$, del cual citamos un par de trabajos en el presente artículo. Finalmente concluyó como necesario el uso de ametralladoras para su matanza pero poniendo en práctica esta medida y aquí radica la gran diferencia- única y exclusivamente a través de las lanchas cañoneras de la Armada, tal y como se había llevado a cabo con bastante éxito en Francia donde «muertos unos y ahuyentados otros, dejaron de ser una pesadilla de los pescadores y el mayor enemigo de su industria ${ }^{30}$.

Dicha comisión se constituyó, reunió e inició su cometido con una celeridad no correspondida tras el establecimiento de la dictadura de Primo de Rivera en el mes de septiembre de 1923, pues fue solicitada el 4 de julio y el día 17 de ese mismo mes ya estaban en Vigo recogiendo información para estudiar éste y otros problemas que afectaban a los pescadores ${ }^{31}$. Sin embargo, todavía en noviembre de 1924

${ }^{29}$ BERNÁRDEZ, A.: «Los problemas de la pesca», Faro de Vigo, 4-7-1923, p.1; «La pesca en Vigo», La Voz de Galicia, 4-7-1923, p. 1; «La pesca en Galicia», La Voz de Galicia, 18-7-1923, p. 1. Véase apéndice. ÁNONIMO: «Nuestra riqueza pesquera», Faro de Vigo, 18-7-1923, p. 1.

${ }^{30}$ ANÓNIMO: «La sardina y los delfines», La Voz de Galicia, 23-11-1924, p. 1.

${ }^{31}$ Ibidem. 
no se había hecho nada al respecto con las consiguientes quejas de los pescadores, los cuales se sentían desamparados ante la arribada de inmensos bancos de sardinas a las Rías Baixas, que atrajeron a numerosas manadas de delfines en tal forma «que los pescadores se ven casi imposibilitados de largar los aparejos, pues aquellos cetáceos se los destrozan materialmente, al ir a buscar el sabroso pez» ${ }^{32}$. Ante lo cual se demandaba a los poderes públicos «una rápida acción en el sentido indicado; esto es, una campaña de verdadera persecución de los delfines, por medio de ametralladoras, hecha por los cañoneros de la Armada nacionalı ${ }^{33}$.

En España dicha resolución ya tenía un raro y esporádico precedente en una Real orden del año 1911, que permitía la persecución de arroaces por parte sólo de ciertos barcos dotados de armas portátiles y ametralladoras ${ }^{34}$. Pero los ensayos realizados para la destrucción de los cetáceos hubo que abandonarlos por ineficaces y por ello en los años de 1925 y 1926 la Dirección general de Pesca desestimó sendas peticiones de los Gremios de Pescadores de los puertos del Cantábrico y la Unión de Conserveros de la Federación del Cantábrico:

«Vista la instancia de la Federación de todo el litoral Cantábrico que cursa V.S. a esta Dirección Gral. de Pesca, he de manifestarle que habiéndose ensayado la medida de perseguir a los cetáceos por medio de cañoneros guardapescas, desde los cuales se disparaba sobre ellos, y no habiendo obtenido resultado he acordado de conformidad con lo informado por la sección $2^{a}$ de esta Dirección Gral., desestimar la instancia referida y significarle a dicha Federación, que puede proponer para su debido estudio otro procedimiento para seguir y ahuyentar a dichos cetáceos que pueda considerarse más eficaz.

Dios guarde a V.S. muchos años. Madrid 13 de Julio de 1926"13.

Sin embargo, al año siguiente otra Real orden, de la que tenemos noticia por una carta del Ministerio de Marina remitida el 12 de noviembre de 1927 al Capitán General del Departamento Marítimo de Ferrol, ordena que se intensifique este método antes desestimado al persistir con especial incidencia en Galicia un problema al que no se le hallaba otra mejor solución:

${ }^{32}$ Ibidem. Véase apéndice.

${ }^{33} \mathrm{Ibidem}$. Véase apéndice.

${ }^{34}$ RODRÍGUEZ SANTAMARÍA, B.: Diccionario de las artes de pesca ..., p. 103.

${ }^{35}$ Archivo General de Marina Álvaro de Bazán (Viso del Marqués, Ciudad Real), Fondo documental de Ferrol, leg. 14.412, copia del escrito de la Dirección General de Pesca de 13 de julio de 1926.

Cuadernos de Estudios Gallegos, Tomo LI, Fascículo 117, Santiago 2004. (Págs. 313 - 362) 
«Ministerio de Marina. Sección de Campaña. Negociado $1^{\circ}$.

Señor Capitán General del Departamento de Ferrol

Excmo. Señor.

A fin de evitar la destrucción de las redes y aniquilamiento de las especies por los arroaces, perturbando el ejercicio de la industria pesquera cuando aparecen en los lugares en que la pesca se realiza, S.M. el Rey (q.D.g.) ha tenido a bien disponer que por los cañoneros afectos a la vigilancia de la pesca se intensifique la persecución de las manadas de los referidos cetáceos en los lugares que los Comandantes de Marina indiquen como más perjudicados.

Lo que de Real orden lo digo a V.E. para su conocimiento y efectos.

Dios guarde a V.E. muchos años.

Madrid 12 de noviembre de $1927 »^{36}$.

Ante lo cual, el 17 de noviembre de 1927, se manda desde Ferrol a los Comandantes de Marina de Pontevedra, Vilagarcía de Arousa y Vigo, indicasen a los Comandantes de las lanchas guarda-costas Gaviota y Dorado los lugares donde debían intensificar la persecución de las manadas de arroaces que les saliesen al paso durante sus cruceros de vigilancia. Transcribimos a continuación los borradores de las órdenes dadas a dichos comandantes:

«Previene que a fin de evitar la destrucción de las redes y aniquilamiento de las especies por los arroaces se sirva indicar a los comandantes de los buques guarda-pescas los lugares más perjudicados, a fin de que por los mismos durante sus cruceros de vigilancia, se intensifique la persecución de las manadas de los referidos cetáceos a cuyo efecto con esta fecha se les dan las oportunas órdenes. Ferrol 17 noviembre 1927.

A los Comandante de Marina de Vigo, Pontevedra, Villagarcía ${ }^{37}$.

«Sres. comandante de los guarda pescas Dorado y Gaviota. Sirvase V. en sus cruceros de vigilancia de la pesca intensificar la persecución de las manadas de arroaces en los lugares que los respectivos comandantes de marina indiquen como más perjudicados a fin de evitar la destrucción de las redes y aniquilamiento de las especies por los cetáceos de referencia. Dios guarde a V. muchos años. Ferrol 17 noviembre de 1927»»3.

\footnotetext{
${ }^{36}$ Ibidem, orden $\mathrm{n}^{\circ} 1(12-11-1927)$

${ }^{37}$ Ibidem, orden $\mathrm{n}^{\circ} 3$ (17-11-1927)

${ }^{38}$ Ibidem, orden $\mathrm{n}^{\circ} 2$ (17-11-1927).
} 


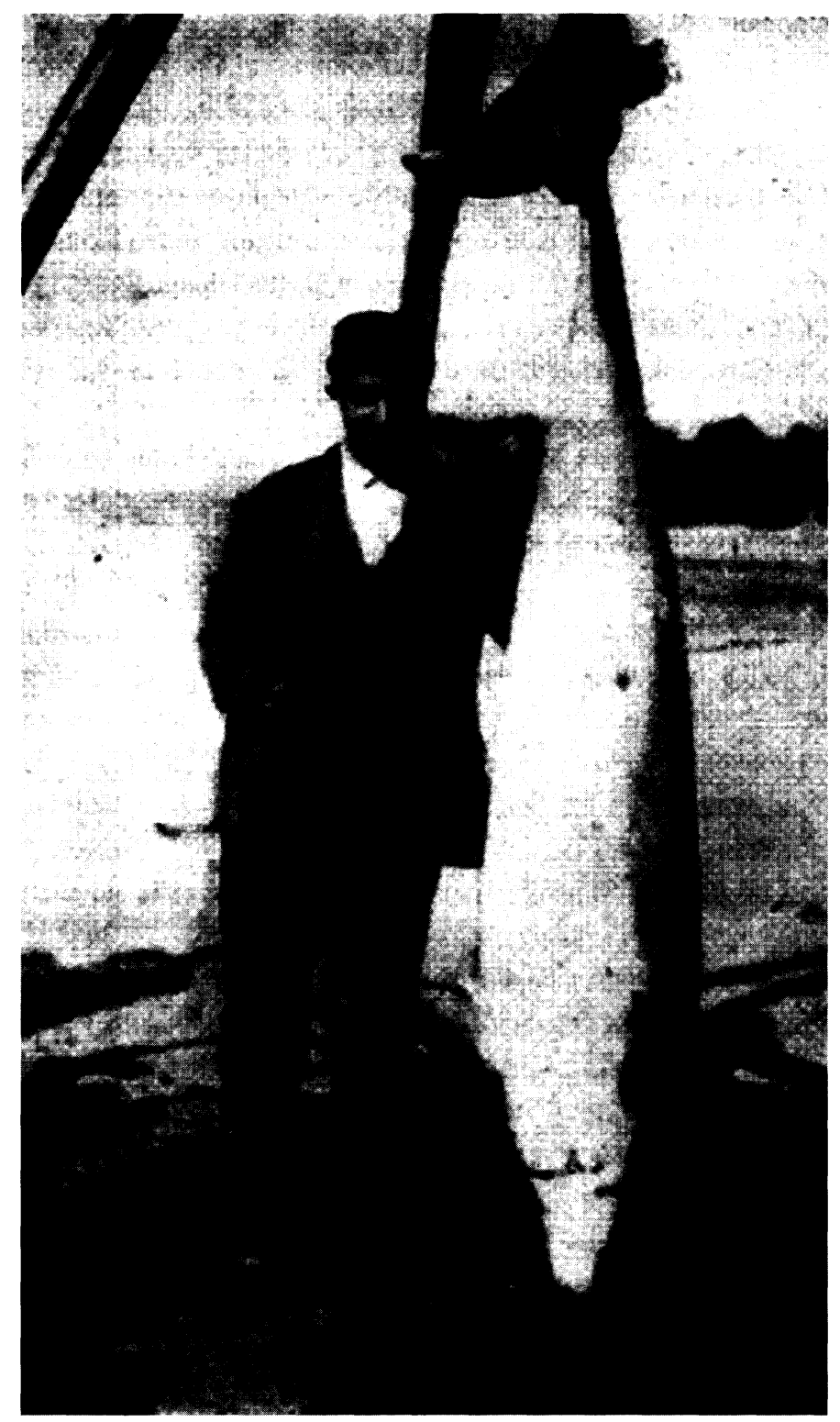

Una hembra de arroaz (delfín mular) de 2 metros de longitud y $104 \mathrm{~kg}$ de peso capturada en Baiona en 1925. Faro de Vigo. 
No es de extrañar que, enterados por la prensa de Vigo, el Pósito de Pescadores de Colindres, el Cabildo de Mareantes de San Martín de Laredo, el Pósito de Pescadores del Cabildo de San Andrés de Castro Urdiales y la Sociedad de Pescadores de Nuestra Señora del Puerto de Santoña, solicitasen al Capitán general del Departamento Marítimo del Ferrol un guarda-costas para la batida de las manadas de delfines. Una petición que fue denegada a través de un despacho remitido desde Ferrol, el 17 de diciembre, al Comandante de Marina de Santander, en este caso alegando una escasez de medios al no hallarse ningún guarda-costas disponible ocupados como estaban cumpliendo su misión en las rías gallegas, al tiempo que -como medida apaciguadora ante una probable protesta- se adjuntaba el escrito ya conocido de la Dirección general de Pesca de 1926 sobre la dudosa eficacia de dicha medida ${ }^{39}$.

Merece la pena detenernos brevemente en las quejas de las sociedades de pescadores de aquellas villas cántabras, ya que su voz en este asunto es el sentir de todos los pescadores. Es interesante, por ejemplo, como reconocen que la pesca del besugo, chicharro y merluza, había desaparecido a lo largo de toda la costa pero no por culpa de los arroaces, sino por la acción devastadora de los barcos de arrastre. Por ello los pescadores subsistían sólo con las capturas de anchoa y sardina, cuya pesca al cebo (pesca al galdeo) provocaba la aparición en las abras y playas de un «ejército inmenso de feroces y malditos arroaces», en tal proporción que provocaban estragos en los cercos y boliches, reducidos a «simples piltrafas» y causando pérdidas de 2.500 a 4.000 pesetas según el presidente del Cabildo de Mareantes de Laredo. En Santoña habían «hecho aparición en estas playas los arroaces en tal proporción que en cuanto se intenta tirar las redes al mar para la captura de esta especie, como es plato exquisito para estos arroaces, intervienen en las redes destrozándolas, imposibilitando al momento cuantas redes se tiren al mar, teniendo que regresar a puerto sin haber podido dar captura a la sardina, que de no haber aparecido estos peces malos y en proporción tan considerable, el pescador habría podido llevar el pan a sus hijos que intranquilos le aguardan para poder quitar el hambre» ${ }^{40}$. Vemos pues, que se trata de una protesta muy similar a la de los pescadores de Vigo en noviembre de 1924, quienes también aducían que ni siquiera podían echar las redes porque inmediatamente eran destrozadas. Pero como todas las demás, las quejas del Presidente del Cabildo de

${ }^{39} \mathrm{Ibidem}$, orden $\mathrm{n}^{\circ} 4$ (12-12-1927), $\mathrm{n}^{\circ} 5$ (12-12-1927), $\mathrm{n}^{\circ} 6$ (12-12-1927), $\mathrm{n}^{\circ} 7$ (13-12-1927), $\mathrm{n}^{\circ}$ 8 (17-12-19927).

${ }^{40}$ Ibidem, orden $\mathrm{n}^{\circ} 7$ (13-12-1927). 
Mareantes de Santoña - del que incluso sabemos por el boletín del Instituto Español de Oceanografía que solicitó el uso de bombas lanzadas desde hidroaviones a semejanza de lo planteado en Francia- no fueron atendidas en base al consabido argumento de lo ineficaz del procedimiento ${ }^{41}$.

Sin embargo, como ya señalamos, a pesar de tan amargas quejas de los cántabros era un problema que afectaba en mayor intensidad a las rías gallegas $\mathrm{y}$, de hecho, los propios pescadores gallegos se percataron de ello cuando faenaban en un litoral diferente como el portugués. Algo para lo que no se hallaba otra mejor explicación que un posible comportamiento distinto entre lo que se suponía eran especies diferentes de delfines en uno y otro lugar, según Ángel Bernárdez, periodista especializado en materia pesquera:

«oyendo decir a algunos pescadores de Cangas que los mismos cetáceos que en las rías gallegas les destruyen las redes no les causan este perjuicio en las costas de Portugal. Puede ocurrir que esto sea obra de la casualidad.... $\rangle^{42}$.

Lo que evidencia, además de ser Galicia el tramo costero de la Península Ibérica más conflictivo, que la causa de ello es la peculiar conformación del litoral recortado en grandes y numerosas rías de enorme riqueza ecológica, reclamo de pescadores y manadas de arroaces.

Y al margen de las rías de Vigo, Pontevedra, Arousa y Muros, idéntico procedimiento de persecución con armas de fuego lo hemos podido documentar en otra ría antaño plagada de fábricas de salazón y redes de xeito para la sardina. Es el caso de la de Ares, donde no fueron raras en los años treinta o cuarenta las batidas de delfines con lanchas de la Comandancia y tripulantes armados con rifles o escopetas, previa protesta también de los pescadores a la respectiva Comandancia ${ }^{43}$.

\footnotetext{
${ }^{41}$ «La aviación coopera a la destrucción de cetáceos», Boletín de Pescas, Instituto Español de Oceanografía, $\mathrm{n}^{\circ}$ 119, julio 1926, pp. 203-204 y «Persecución de arroaces», Boletín de Pescas, IEO, $\mathrm{n}^{\circ} 129$, mayo 1927, p. 154.

${ }^{42}$ BERNÁRDEZ, A.: «La pesca en Galicia...», p. 1. Véase apéndice.

${ }^{43}$ Comunicación personal del ex-capitán ballenero Miguel López Pérez.
} 

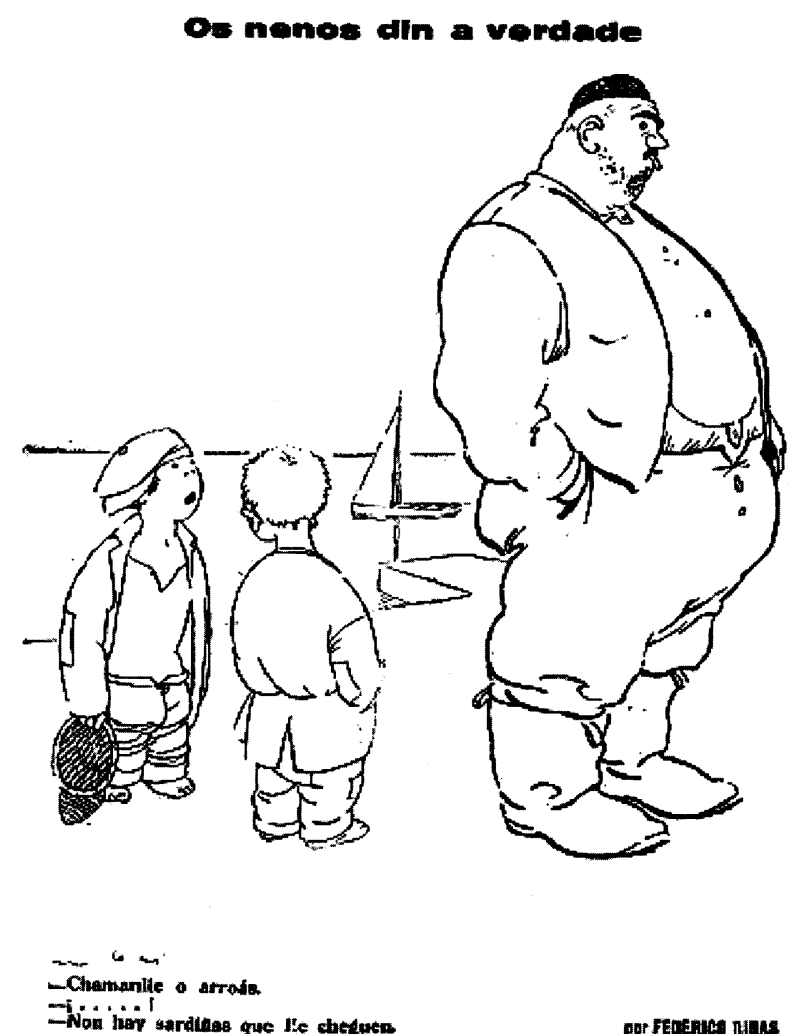

por fEotana nas

-Le llaman el arroaz. -No hay sardinas que le lleguen.

Interesante ilustración publicada en la portada del Faro de Vigo del 21 de mayo de 1925, la cual denota la fuerte connotación negativa hacia el delfín, entre la gente de mar, como esquilmador de la pesca. 


\section{LOS INTENTOS DE INDUSTRIALIZACIÓN DE LOS DELFÍNIDOS}

- El fracasado precedente del Estrecho de Gibraltar. - Infructuoso intento de un fomentador catalán en Galicia.

En los años posteriores perdura la misma percepción del problema-quizás algo aminorado-y en este contexto se suceden los intentos por establecer una industria sobre la base de la explotación de los pequeños cetáceos, orientada a la comercialización del aceite fundamentalmente. En 1941 tenemos vaga noticia de la autorización a una empresa de un ensayo para la industrialización del delfín ${ }^{44}$. Luego, en 1954, la conservera de Ceuta Carranza intentó sin éxito establecer una industria basada en el aprovechamiento y comercialización de la carne y aceite del calderón del Estrecho de Gibraltar, donde tanto abunda esta especie ${ }^{45}$. Para este propósito emplearon un pequeño pesquero de bajura tripulado por cuatro marineros pertrechados con un par de arpones de mano (de punta articulada) ${ }^{46}$. No es difícil imaginar que esta precariedad de medios, unido a la complejidad de arponear estos cetáceos desde la proa de una inadecuada embarcación, desbaratase esta tentativa que no consiguió capturar ni un solo cetáceo.

Poco después, en 1956, desde Barcelona se plantea un nuevo intento que tiene a Galicia como hipotético centro productivo de aceite de delfín, contando con el concurso de una de las dos industrias balleneras gallegas. La proposición parte de la firma de Hospitalet de Llobregat Brugarolas Sociedad Anónima que, fundada en 1885 , se dedica a la producción de lubrificantes, detergentes, aceites, grasas, jabones industriales y otros productos similares. Era una de las industrias de Cataluña que, aprovechando la desprotección arancelaria con la que se favorecía a los fabricantes de margarinas y aceites industriales españoles, podía abastecerse ocasionalmente con el aceite de cetáceo de producción nacional, en este caso de Industria Ballenera Sociedad Anónima (IBSA), a la cual presenta Santiago Brugarolas Canals

${ }^{44}$ Se trata de la Orden de 4 de febrero del Ministerio de Industria y Comercio por la que se concede a Antonio Pons y Ramírez y José Luis Estrada y Segalerva la exclusiva, a título de ensayo y durante dos años, de la industrialización del delfín en la costa comprendida entre Torre Guadalmesí y Cabo de Gata y desde Cabo Tortosa a Cabo Creus; Boletín Oficial del Estado, 14 de febrero de 1941, p. 1.032. Véase también AGUIRRE FANIQUE, L.: «España vuelve por sus fueros balleneros», Información comercial española, Madrid, 1952, pp. 336-342.

${ }^{45}$ Comunicación personal del ex-capitán de la flota ballenera gallega Miguel López Pérez y del ex-marinero -también de la flota ballenera- Juan Oliva Badillo, el cual además participó en esta esporádica empresa.

${ }^{46}$ Ibidem. 
su proyecto ${ }^{47}$. El 26 de octubre dicho empresario remite una carta a las oficinas de IBSA en A Coruña en la que, con toda cautela, propone un negocio relacionado con el aceite, sin especificar nada más, aguardando antes una oferta económica:

«La finalidad fundamental de este proyecto, es como ya he dicho, producir un buen aceite, cantidades que pueden ser importantes de harina y trabajar todo el año para poder atender el consumo nacional, entre lo que ya obtienen ahora y lo que se consiguiera con el procedimiento o nueva orientación que les ofrezco.

Les estimaré me digan si les interesa tomar en consideración ese proyecto y, aunque de una manera simplista, las condiciones -siempre modestas- que podrían concederme» ${ }^{48}$.

La contestación de IBSA, unos días después, no puede ser otra que recibir con interés y moderada expectación dicho proyecto aguardando, por su parte, mayor claridad expositiva a la que atenerse para dar cumplida respuesta:

«Como Vd. comprenderá, todo cuanto afecte al mejor orden de esta Industria, nos interesa; pero no podemos decir las condiciones de tomar algún proyecto que no conocemos» ${ }^{49}$.

El industrial catalán procede a corresponder a los gallegos elaborando un informe de cuatro folios -que incluimos en el apéndice- en el que pone de relieve lo que, a su juicio, son los inconvenientes de la industria ballenera (inactividad invernal, pesca de altura, rapidez en la putrefacción de los cadáveres), en contraste con las ventajas de la industria del delfín (actividad pesquera ininterrumpida y costera, con barcos de poco tonelaje, reducción del tiempo empleado en la manufactura gracias al menor tamaño del delfín y la consiguiente mejora en la calidad de la carne, del aceite y la harina). Si bien, el tamaño -contrariamente a lo que pensaba Santiago Brugarolas- sumado a la innata rapidez y agilidad de todas las especies de delfines, lejos de ser una ventaja, representaba una importante dificultad a la hora de capturarlos en gran número y el menor tiempo posible, siempre que el método utilizado fuesen las batidas con arpones y no con red, una posibilidad en ningún momento sugerida ${ }^{50}$. Además de aportar una descripción biológica de las tres especies de delfines que serían objeto de explotación, compara la calidad de su

\footnotetext{
${ }^{47}$ Archivo del autor, Caja clientes A-Z (1951-59), carpeta Brugarolas.

${ }^{48}$ Ibidem, 26-10-1956.

${ }^{49}$ Ibidem, 30-10-1956.

${ }^{50}$ Ibidem, 8-11-1956. Véase apéndice.
} 
aceite con el de la ballena, escualo y los aceites vegetales (oliva, ricino, linaza), destacando la calidad de este otro cuya producción quería fomentar, al considerarlo similar al de ballena ${ }^{51}$. Aparte del supuesto incremento en el margen del beneficio que supondría la continuidad de la actividad pesquera a lo largo de todo el año al aumentar las ventas, realiza una estimación de la ganancia en torno a las 600 pts. por cada $100 \mathrm{~kg}$ de delfín, estableciendo en 8 y 6 pts. el precio por kilogramo del aceite y la harina, respectivamente, y contando con una merma del $15 \%$ en el proceso de obtención del aceite. Merma que en relación al peso medio -según éldel delfín (un $6 \%$ de $40 \mathrm{~kg}$ ) equivaldría a un beneficio aproximado de $235 \mathrm{pts}$. por delfín ${ }^{52}$.

El industrial catalán se hallaba convencido de la favorable acogida de su proyecto y el éxito del mismo en manos de los gallegos. Sin embargo, ello acontece durante el parón invernal de la industria ballenera lo que, unido al desinterés de IBSA por el proyecto, demora la respuesta más de un mes -previa insistencia del catalán ${ }^{53}$ - rechazando el proyecto con el consiguiente resquemor del industrial catalán:

«Hemos visto, con todo detenimiento y la natural atención, sus indicaciones sobre la posibilidad de beneficiar «delfines».

Por el momento, no nos parece esta la coyuntura en que pudiéramos ejercitar esa actividad; pero, si en el futuro nos decidiéramos a intentarlo, tendríamos mucho gusto en darle noticias de ello.

Como nos será siempre grato todo motivo de relación con $V d . »^{54}$.

En esta aparente descortesía también pudo influir el hecho que, con anterioridad, ya se hubiese producido cierto desencuentro en la relación comercial entre ambas industrias, habiendo interrumpido la firma catalana, a principios de año, las adquisiciones de aceite alegando el fuerte frío reinante en aquella región que afectaba al normal funcionamiento de su producción de hidrógeno ${ }^{55}$. Todo ello tras haberse producido las constantes reclamaciones -debidamente correspondidaspor el retraso y envío incompleto de una partida de bidones desde Galicia (faltaban 12 de un total de 112), las habituales diferencias en la graduación de la acidez del

\footnotetext{
${ }^{51}$ Ibidem.

${ }^{52}$ Ibidem.

${ }^{53}$ Ibidem, 10-10-1956.

${ }^{54}$ Ibidem, 24-12-1956.

${ }^{55}$ Ibidem, 10-2-1956.
} 
aceite y en el pesaje en el punto de origen y destino (158 $\mathrm{kg}$ de diferencia), reclamando que en el futuro les dispensasen toda su atención para evitar incómodas y violentas reclamaciones desde Barcelona ${ }^{56}$.

Pero sin duda la falta de consistencia de un proyecto inviable técnica y económicamente para una industria especializada en la captura y procesamiento de enormes cetáceos fue la razón, junto a la coyuntura a la que se alude desde IBSA, de este desencuentro empresarial. Téngase en cuenta, por ejemplo, que para igualar el peso de un solo rorcual común de tamaño medio (entre 30 y 80 tons.), no hablemos ya de un rorcual azul de 120 toneladas, habría que acabar con la vida de varias manadas de delfines comunes (con un peso cada uno entre 70-100 kg) hasta sumar varios cientos de ejemplares, siendo además su aceite de peor calidad. De su informe se desprende que Santiago Brugarolas Canals no tenía en cuenta tales circunstancias, como lo poco apto de un barco ballenero para arponear delfines o que de llevarse a la práctica con un mínimo de profesionalidad supondría la extinción, en cuestión de poco tiempo de casi todas las manadas de delfines de la costa gallega y, por tanto, del recurso natural sobre el que se sustentaba la producción de dicha industria.

«Siento no les interese ese asunto, por la oportunidad que ahora tendría, en que las necesidades de aceites y grasas orgánicos son ya importantes y progresivas, hasta el punto de que en las conclusiones de la II ponencia en el reciente Congreso Nacional Oleícola celebrado en Jaén, se propone la importación de 1.500 toneladas de grasas aptas para hidrogenación y otras 2.500 toneladas de aceites de pescado para el mismo fin. Todo esto y el interés que el Gobierno tiene ahora en estos asuntos, me hacia confiar en la aceptación de Vds. de esa cuestión, que sigo creyendo muy interesante» ${ }^{57}$.

Se trataba, pues, de un negocio poco atractivo para los armadores coruñeses de IBSA puesto que, independientemente de si conocían o no las fracasados intentos en el pasado, tendrían cierta idea de la inviabilidad de esta industria. Además, los intereses empresariales de la ballenera gallega en aquel momento -la coyuntura a la que se refieren- eran bien diferentes a los de Brugarolas, porque IBSA ya atravesaba suficientes dificultades en su proceso de consolidación tras el comienzo de su actividad en 1951, como para embarcarse en nuevas inversiones de alto riesgo cuando eran otras las prioridades. Nos referimos, por ejemplo, al tener que afrontar una ampliación del capital social, sufragar la constante modernización y puesta

${ }^{56}$ Ibidem, 2-1-56, 14-1-56, 18-1-56, 21-1-56, 28-1-56, 10-2-56, 17-2-56, 25-2-56.

${ }^{57}$ Ibidem, 28-12-1956. 
a punto de la factoría de Caneliñas en Cee o la devolución de los créditos hipotecarios concedidos para la puesta en marcha de la industria ballenera, tanto inmobiliarios -las factorías-como navales con la adquisición de dos barcos balleneros ${ }^{58}$. En aquel tiempo el interés de IBSA no era reconvertirse industrialmente, ni diversificar su actividad, sino - con buen criterio- expandirse en España para afrontar en una mejor situación su precariedad en medio de un mercado abastecido con miles de toneladas de aceite de importación ${ }^{59}$. $Y$ en ello estaban inmersos cuando recibieron esta propuesta, puesto que habían adquirido en 1954 parte de la maquinaria y los dos barcos de Industrial Marítima S.A. (que cerró su factoría de Benzú en Ceuta), alquilando uno a la factoría de Getares (Algeciras) y destinando el otro al abastecimiento de la factoría de Balea (Cangas del Morrazo), tras la firma de un convenio comercial con la conservera Massó Hermanos SA, propietaria de esta otra factoría ${ }^{60}$.

Por lo tanto, la industria ballenera de Galicia nunca se implicó en la pesca de pequeños cetáceos y el único dato al respecto que podemos aportar se refiere a la muerte de algún calderón practicando o comprobando en alta mar el cañón lanzaarpones (a veces incluso probando con algún gran escualo).

\section{CONCLUSIÓN}

A lo largo de este artículo hemos podido comprobar cómo los delfines representaron un problema para la vulnerable actividad pesquera de bajura de antaño, al mismo tiempo que se convirtieron en el chivo expiatorio de la escasez de pescado, pero cometeríamos un error al considerar que ello fue siempre así o al menos en el caso de todas las artes de pesca. La colaboración entre pescadores y delfines está documentada desde la antigüedad perviviendo todavía en aquellas comunidades de pescadores que han conservado el carácter más ancestral de la pesca, aunque en la mayor parte de los casos cabe considerarla como una relación oportunista por parte del hombre que se servía o sirve de los cetáceos para localizar y atrapar los bancos de peces, como la pesca al mansio o manjúa, muy frecuente antaño en las rías gallegas. En este caso el pescador descubría los bancos de peces gracias a los delfines y empleando las embarcaciones más rápidas navegaban tras las touliñas o arroaces hasta que éstas se detenían en una zona alternando las inmersiones y

\footnotetext{
${ }^{58}$ Tesis doctoral inédita del autor

${ }^{59}$ Ibidem.

${ }^{60}$ Ibidem.
} 
salidas a respirar, señal de que allí estaba localizado el banco de peces que los pescadores rodeaban con el cerco llamado traíñ ${ }^{61}$. Xaquín Lorenzo alude a este método de pesca e incluso a ciertos lugares en la costa, en este caso un árbol, desde donde se avistaban los delfines que delataban la presencia de los peces:

«Pra pescar ó mansío ou touliñal, guianse polas tolinas ou delfins que persiguen a sardiña e de que xa falamos.

En Viveiro habia unha arbre, que xa desaparecéu, chamado o "arbre da paciencia», onda o que se puñan os mariñeiros á espreita do choutar das tolinas; cando as vían era sinal de que viña o peixe e entón saían bogando até acadal-o banco das sardiñas e faguel-o cerco» ${ }^{62}$.

El marinero de antaño aprendió a interpretar el comportamiento de las manadas de delfínidos para descubrir el lugar donde se encontraban los bancos de peces, conocer el tamaño y dirección de estos cardúmenes, su profundidad, además de la especie de pescado que allí podría capturar. Es por ello que consideramos que antiguos modos de pescar tengan su origen en la imitación del comportamiento de las manadas de delfines, que acorralan los asustados bancos de peces contra la costa - un cantil o playa- agitando la superficie del agua al golpearla con sus aletas caudales y reiterados saltos del cuerpo. Nos referimos, por ejemplo, a la pesca ó balo que consiste en embalar (de ahí el nombre de balo), es decir, asustar a los peces contra la red golpeando con los remos la superficie del mar ${ }^{63}$. Pescar ó balo se realizaba a lo largo de toda la costa gallega -y todavía lo hacen no pocos marineros para impedir, por ejemplo, la salida de los peces al levantar un cerco-, aunque antaño fue un modo de pesca controvertido por el hecho de asustar el pescado temiendo no volviese. Por esta razón en la Edad Media fue prohibido en Pontevedra ${ }^{64}$ y en la Edad Moderna era rechazado por los propietarios de los cercos, que acusa-

\footnotetext{
${ }^{61}$ Comunicación personal del ex-capitán ballenero Miguel López Pérez.

${ }^{62}$ LORENZO FERNÁNDEZ, X.: Historia de Galicia (dirigida por Ramón Otero Pedrayo), volúmen II, Akal, 1979, p. 352.

${ }^{63}$ Comunicación personal del ex-capitán ballenero Miguel López Pérez.

${ }^{64}$ «El balo, alboroto que se armaba a base de golpes, gritos y agitación de las aguas para obligar a los peces a precipitarse en los trasmallos, fue prohibido por las ordenanzas de Pontevedra con la idea-equivocada-de que el pescado, asustado, no volvía más por aquel lugar. Antes de su prohibición, el balo se empleaba en la Edad Media por lo menos en las rías de Arosa y Pontevedra, y todavía hace poco quedaban en la ría de Arosa los célebres baleiros, pescadores que, acotando un arco de playa con una red, balaban o azuzaban el pescado contra ella»; FERREIRA PRIEGUE, E.: Galicia en el comercio marítimo medieval, Fundación Barrié de la Maza, A Coruña, 1988, p. 142.
} 
ban a los jeiteiros de espantar la sardina fuera de las rías ${ }^{65}$. Muy lejos de nuestro ámbito de estudio, como es la costa de Mauritania, existe un claro ejemplo de esta imitación del método de pesca de los delfines, que además colaboran con los hombres: desde la orilla con sus redes los pescadores golpean la superficie del agua aguardando la llegada de los delfines que, desde alta mar, hacen lo propio asustando el banco de peces contra las redes para ganancia de unos y otros ${ }^{66}$.

Pero a medida que el mundo de la pesca se transformó y modernizó con la introducción de las grandes artes de pesca, escaseando cada vez más el pescado, los pequeños cetáceos se convirtieron en una alimaña marina y chivo expiatorio que había que eliminar de las aguas costeras. La mortandad afectó en mayor medida al arroaz o delfín mular y menos al delfín común. Así se deduce de las fuentes documentales y bibliográficas que, además de delfines sin especificar, aluden principalmente a arroaces y en menor medida a delfines comunes con sus diferentes denominaciones (touliñas, etc.). Todo lo cual coincide con lo que sabemos en la actualidad sobre la presencia de cetáceos costeros, pues es el arroaz el más abundante cerca de la costa alimentándose cerca de las playas, cantiles e internándose en las rías, mientras que el delfín común es menos costero pero también llega a entrar ocasionalmente dentro de las rías en grandes manadas, lo cual ya es más esporádico en el caso de las marsopas. Por último, a lo largo de tanto tiempo cabe suponer capturas de otras especies, que desarrollan su actividad vital bastante más lejos del litoral como los delfines listados, los grises, los calderones y otros.

En Galicia esta pesca y persecución se realizó de manera individualizada (por cada pescador o pesquero), ocasionalmente (los delfines eran arponeados o tiroteados al aproximarse a la proa de los barcos) y accidentalmente (cetáceos ahogados al enmallarse en los aparejos de pesca). Las campañas de exterminio cabe considerarlas como puntuales (las corridas de arroaces de Pontevedra) o ineficaces (la utilización de patrulleras de las comandancias). En cuanto a las tentativas de industrialización que se remontan al siglo XVIII no pasaron de eso, meros intentos, siendo especialmente interesante el proyecto propuesto a IBSA por un fomentador catalán.

${ }^{65}$ «Desde últimos de dicho noviembre continuava la pesca del geito hasta fines de enero que cesava, no permitiéndose que durante el uso de las traiñas o cercos reales se pescase a él por la justa causa de que viniendo la sardina como viene de la mar alta a pastar en las rías, los jesteyros la espantan con el baleo y otros arvitrios que toman para que vaya a embestir a sus redes de jeyto con cuyo motivo buelve a salir a la mar», ANÓNIMO: «Sucesos acaecidos sobre la pesca de la sardina desde el establecimiento de jávegas en Galicia, y reflexiones sobre este fruto y modos de cogerlo», Pesquerías Tradicionales y conflictos ecológicos (1681-1794), Ministerio de Agricultura, Pesca y Alimentación, Madrid, 1991, pp. 285-290.

${ }^{66}$ COUSTEAU, J.Y.: Los secretos del mar, $\mathrm{n}^{\circ}$ 32, Ediciones Folio S.A., 1994, pp. 72-86. 
Fue la de Galicia la costa española donde se dio con mayor intensidad este problema pesquero y, por consiguiente, donde se libró la más importante persecución contra estos cetáceos, por lo ya explicado en relación a la peculiaridad geográfica de la costa gallega con sus grandes rías, que daban cobijo a delfines y a la industria de salazón más importante del país sobre la base de ingentes capturas de sardinas. Es por ello que en ningún otro lugar de España se realizaron las corridas de arroaces o algo parecido, ni tampoco el problema fue en no pocas ocasiones objeto de tanta protesta y portada de periódicos. Tampoco en ningún sitio como Galicia se involucró tan activamente a las lanchas de las comandancias o se enviaron desde Madrid comisiones técnicas, como la de 1923 en Vigo, encargadas de estudiar y proponer soluciones a un problema sobre el que ya se había preocupado el Padre Sarmiento en el siglo XVIII, que consideraba a los arroaces como el enemigo capital de la sardina ${ }^{67}$.

Pero no fue ni mucho menos Galicia o España un lugar que podamos destacar por la matanza de delfínidos si lo comparamos con países como Japón (donde todavía hoy se pescan por miles para consumo de su carne), Perú, Islandia, las islas Feroe u otros que, como Francia y Canadá, incluso recurrieron a los bombardeos aéreos de las manadas de pequeños cetáceos ${ }^{68}$.

Si el aumento del consumo de pescado y del tamaño de las artes de pesca en la Edad Moderna supuso un incremento de la persecución de lo delfines, después de la conflictiva década del 1920, la persecución disminuye sustancialmente llegando al ecuador del siglo XX, lo cual posiblemente guarde relación con la progresiva reconversión de la flota gallega y española a la pesca de altura o gran altura y de la industria de la salazón a la conserva. Desde entonces las noticias (1941, 1954, 1956) se refieren a los intentos por industrializar los delfines costeros para sacar provecho comercial de ellos, al margen del problema pesquero de antaño al que ya no se alude.

Y es que el más que probable descenso del número de manadas de delfínidos en nuestras costas, la mejora de la calidad de vida de los pescadores con el aumento de los ingresos económicos (ampliando el margen de pérdidas asimilable), la expansión de la pesca de altura en detrimento de la actividad pesquera y salazonera

${ }^{67}$ SARMIENTO, M.: «De los atúnes y de sus transmigraciones y conjeturas sobre la decadencia de las almadrabas; y sobre los medios para restaurarlas», Pesquerías Tradicionales y conflictos ecológicos (1681-1794), Ministerio de Agricultura, Pesca y Alimentación, Madrid, 1991, p. 81.

${ }^{68}$ CAWARDINE, M. et al:: Ballenas, delfines y marsopas, Omega, Barcelona, 1999, pp. 46-47. «La aviación coopera a la destrucción de cetáceos», Boletín Español de Oceanografia, $\mathrm{n}^{\circ} 119$, julio 1926, pp. 203-204.

Cuadernos de Estudios Gallegos, Tomo LI, Fascículo 117, Santiago 2004. (Págs. 313 - 362) 
dentro de las rías, el cegamiento de éstas con los sucesivos depósitos aluviales de los ríos reduciendo dicha actividad y la presencia de cetáceos, la escasez de sardinas consecuencia de la sobrepesca y la mayor resistencia de las redes con el uso de fibras sintéticas reduciendo los daños, ha contribuido a disminuir este problema pesquero aquí tratado, si bien todavía no ha desaparecido. En consecuencia su pesca o matanza deliberada no es una práctica erradicada en la costa gallega y resto de España, aunque cabe considerarla como esporádica o anecdótica en comparación a los tiempos pasados. Ahora son otros -y mucho más graves- los problemas que afectan al hombre como pescador en la interacción con el medio marino la contaminación, la sobrepesca y en definitiva la destrucción del ecosistema marino-, con la salvedad que ahora no hay otro culpable o chivo expiatorio más que él mismo. Pero esto podrá ser materia prima de historiadores en el futuro, como lo ha sido para nosotros el viejo problema pesquero del que nos hemos ocupado en el presente artículo.

\section{APÉNDICE}

1757, marzo, 9.

Carta de Fr. Martín Sarmiento a su hermano Javier, Ministro de Marina en Pontevedra, sobre los problemas de la pesca en la ría de Pontevedra: la retirada de los privilegios y el modo de matar los arroaces.

FILGUEIRA VALVERDE, X. y FORTES ALÉN, M. X.: Fr. Martín Sarmiento. Epistolario, Consello da Cultura Galega, Santiago de Compostela, 1995, pp. 63-64.

Hermano Javier:

Recibí tu carta y todos los papeles inclusos y siento que el privilegio al patrón de barco haya dado ya en el suelo. Acuérdate que ya me lo temía ahí. Mañana caerá en el suelo el privilegio de la sal fiada. Llevará el diablo toda la pesquería y viva el valor español. ¿Y qué quieres que haga yo?

El Ministerio está inaccesible. Cada día salen providencias encontradas. Lo de Ferrol va por la posta.

Dicen que hay quintas y levas con que tendremos demasiado.

Con señalar en cada puerto 20 o 30 barcos no más y cuyos patrones sólo tuviesen fijo el privilegio y los demás, aunque tuviesen barcos, no gozasen de él hasta que hubiese 
vacante, y por antigüedad de fábrica de barco, se quitaban los abusos y fraudes, se sostenía la pesca, no se aumentaba el número de libertados y la expectativa segura animaría a hacer más barcos.

Pero ya estoy cansado de experimentar, que si los arbitrios no son muy violentos, jamás se plantarán. Así, ríete, que yo me río también de esa fantasma bien común y alivio de pobres. No es eso del siglo, del año, del mes, ni del día.

El espantar los arroaces tiene mil arbitrios, pero como non é uso nen costume tentar alguno de ellos, es excusado gastar papel y dejar a estos cerrilísimos que recurran a los conjuros de los gurumantes, que están en Ons.

El modo de apurar los arroaces es el que ahí inventó la avaricia para apurar las ostras, ameixas, berberichos, tranchos, lenguados, rodaballos, etc. Si se apuran las semillas se apurarán esos géneros. Y para apurar los arroaces, el modo es apurar su semilla.

Los ingleses apuraron los lobos de su isla, en virtud de batidas a tiempo. ¿Y por ahí no se debía entablar batida de arroaces? Más útil traerá un arroaz por el saín, que un lobo.

Aún no sé si es delfín el arroaz. Sé que es el marsovin francés (marsouin, maris-surllus, puerco de mar). Por eso no sé si el arroaz tiene huevas o si pare hijos vivos como los cetáceos. Averígualo y avísame. Sean ovíparos o vivíparos, se debe observar cuando están en huevas o están en celo. Entonces se debe hacer la batida.

Los arroaces andan en tropa y sacan fuera el cuerpo. Con cercar esa tropa con una red común y por fuera con un cerco de barcos, o al contrario, siempre vendrán a los barcos para escapar. Entonces con francadas, dardos, arpones, escopetas, lanzas, etc. se les puede acometer de seguro. Las redes podrán hacerse de juncos, de esparto, de mimbres, de gestas, etc. que cuesten poco y tengan las mallas muy anchas.

Pero reinando ahí la vulgaridad de que la sardina huye de la sangre del arroaz, es excusado pensar en arbitrio alguno. Creíble es que el celo y huevas sean por la primavera. Entonces no hay sardina, ni pesca, y así no hay motivo para el temor.

Si ahí se ríen de la batida diles que yo me río de sus quejas y me compadezco de las batidas que van a hacer de lobos en la Ponte-nova. Al modo que se pescan las ballenas se deben pescar los arroaces. Es cierto que el saín costearía el gasto y defendería la batida a la pobre sardina.

En uno, ni en cuatro, ni acaso en diez años, no se apurarían los arroaces, pero cada día irían a menos. Las redes exteriores de los atunes son flojas y de esparto.

Dirían que no sabrán armar. Pues que traigan uno de los que han ido a la pesca de las ballenas. ¿Y qué sé yo? Acaso vendrían a las redes algunos atunes y era otro tanto en oro.

Como no ví el arroaz vivo entero en tierra, no puedo regular su paso y figura. El hecho es que huye de la candorca, o peixe espada. Entablada la armadura para los arroaces, acaso serviría para las ballenas cuando una, no siendo tiempo de sardina, apuntare a la ría.

En lo demás no sé que te digo. Sólo digo que deseo lo mismo que tú. Pero, ¿qué he de hacer? Rogar a Dios que se consiga y que te guarde muchos años.

Madrid y marzo 9 de 1757.

Tuyo, fray Martín.

Remito la Guía para forasteros porque me acordé.

Hermano Javier. 
1758, abril, 11 .

Carta de Fr. Martín Sarmiento a su hermano Javier, Ministro de Marina en Pontevedra, sobre el modo de matar los arroaces de la ría de Pontevedra aprovechando su ceguera.

FILGUEIRA VALVERDE, X. y FORTES ALÉN, M. X.: Fr. Martín Sarmiento. Epistolario, Consello da Cultura Galega, Santiago de Compostela, 1995, pp. 102-103.

Hermano Javier:

Recibí tu carta y siento se haya desbaratado el casamiento del heredero de las Hachas con la hija de la Serra. Si lo mucho que los señores de las Hachas han de gastar en venir, estar y volverse, se aplicase per modum datis, no habría resultado el embarazo.

Siento que se haya subido la sal, pero es menos violento arbitrio que el de repartir.

He leído por acaso que por el mes de junio se vuelven ciegos los arroaces y que andan desatinados corriendo de aquí para allí, sin ver gota en tanto mar. Y que en el Norte ese es el tiempo en que los cogen a centenares, moliéndoles a palos, lo que no pueden ejecutar en otros meses, pues se les restituye su antigua vista.

Comunica esta útil noticia a todos los de esa ría y haz que observen si los arroaces al acabar el mayo, todo junio y principios de julio, tienen algunos movimientos desatinados que hagan creer que entonces andan ciegos en virtud de que en aquel tiempo les nace una membrana delante de los ojos que les estorban el ver.

Siendo esto así como no dudo de la veracidad del escritor moderno que aún creo que vive, se podrán idear ahí mil modos de matar arroaces y de conjurar a palos los guzumantes das illas, no espantándolos hacia el mar, sino hacia la costa, en donde se podrán con facilidad o coger o matar en aquel mes. Ahora creo que aquellos arroaces que el famoso Jacobo vio en el puente, serían tales que con su ceguera desbarrarían hacia allí.

El hecho es que no venían siguiendo sardina hasta el puente. Luego vinieron ciegos, sin ver por donde flotaban. Si alguna vez vienen al puente o a los peiraos, nótese en que mes lo hacen y se sabrá ahí cuando tienen la membrana en los ojos y cuando no.

Supongo se reirán ahí de esta noticia y no habrá diablos que los disuadan de los guzumantes o nigromantes. Pero tú no eches al trenzado esta noticia, pues podrá traer utilísimas resultas si se sabe aprovechar de ellas.

Alégrome que se hayan sembrado las semillas y ruego a Dios que peguen las más de ellas.

Adiós

Madrid y abril 11 de 1758.

Tu hermano fray Martín.

Hermano Javier. 
Antes de 1859.

\section{Descripción en verso del poeta local José Benito Amado sobre las corridas de arroaces en Pontevedra.}

La Perseverancia, año I, 13 agosto $1859, n^{\circ} 46$.

Con motivo de los preparativos que se están haciendo para una corrida de delfines en la Peregrina, y habiéndose agotado la tirada que hemos hecho del número anterior, reproducimos hoy el siguiente fragmento tomado de una leyenda referente al siglo XIV, escrito hace algunos años por nuestro estimado y erudito colaborador Sr. Amado, y en el que se describe lo que era en antiguos tiempos este raro espectáculo.

Brillo risueño el más hermoso día cuando el sol por oriente salió al cielo, frescura, luz, aromas y alegría por todas partes respirando el suelo. En su esplendor bellezas y armonía natura se ostentaba y de consuelo ese supremo manantial fecundo enamoraba en su concierto al mundo. Las hojas en el árbol susurraban al blando soplo de una brisa pura, las fuentes a la luz reverberaban las flores prodigaban su hermosura, las aves en los árboles cantaban, el cauce murmuraba en su frescura, y respiraban vida, encanto, amores, aves, árboles, fuentes, cauce y flores.

Hora de regocijo y de alborozo, de contento solaz y alegre fiesta fue aquella en que se vieron terminadas los bélicos aprestos y faenas.

Costumbre por los tiempos consagrada de muy antiguo ha sido en esta tierra (en que el trabajo es la unidad más noble) coronar la más rústica tarea. Un ramo de laurel, mirtos y flores y doradas naranjas, el emblema es el premio que obtiene útil trabajo; y al terminar contentos una empresa, con el ramo de la obra se corona, y con cantos y fiestas se celebra. Surtas las naves en tranquilo puerto, al aire erguidas las cruzadas vergas ostentaban en medio de las aguas flámulas, gallardetes y banderas. De gozo y de placer enajenados los marineros cantan, bullen, juegan, forman danzas de espadas, muy vistosas que sus costumbres bélicas demuestran, y otras mil caprichosas diversiones con que gozan, se esplayan y recrean. Entre los varios juegos que aquel día regocijan del Lérez las riberas, una grande corrida de delfines con aparato y pompa se celebra. Es este un espectáculo muy raro, mejor que el de los toros y otras fiestas, donde reina el bullicio y la alegría y se prueba también maña y destreza.

Un populoso barrio al pie de Helenes se estiende por la orilla que el mar besa, famoso por sus buenos pescadores, por su esplendor, su fausto y su riqueza. Los marineros de este antiguo barrio, preparados de red de mallas gruesas de cuerdas bien seguras fabricada, la venida del mónstruo-pez acechan. Fuertes arpones los robustos brazos cual lanzas de batalla unos blandean, otros de relucientes anchas dagas armada tienen la nervuda diestra. Quien ostenta un rejón, quien una pica quien encintada y singular saeta 
quien un lazo de cuerda corredizo, quien banderillas o aguzadas flechas.

Un Pueblo inmenso en la risueña orilla la plenitud del mar ansioso espera para ver el encierro de los mónstruos y contemplar tan divertida fiesta. Cien chalupas y góndolas las aguas cruzan, vienen y van de gentes llenas, y en la orilla, en la mar y en las alturas flamean mil pañuelos y bandera. Hierve la gente en fiesta y rebullicio entre undulantes grasas oro y sedas un pintoresco cuadro presentado aquella multitud de gozo inquieta. Los ojeadores la señal dirigen de que el marino mónstruo ya se acerca, y todos callan, y la vista espacian por aquel mar que en su creciente reina. Mas cuando todos descuidados miran la superficie sosegada y tersa súbito el grande pez raudo surgiendo con fuerte resoplido se revuelca, y un rumor se levanta por la orilla de susto, de contento y de sorpresa.

Tras el primero vienen otro ciento que corren, saltan, se hunden y aletean resurgen agitados, $\mathrm{y}$ en mil giros cruzan a su placer dando mil vueltas, y veloces por medio de las aguas con rudo impulso y sorprendente fuerza cortando la corriente impetuosos corren mas que un caballo a la carrera. Ya paran, ya se grupan y respiran y de nuevo corriendo se atropellan, dando al aire violentos resoplidos que el agua a chorros en su torno elevan. Al pasar, de una orilla a la otra la red se tiende, el paso atrás les veda, y crecen la ansiedad y la algazara sonando cien bocinas y trompetas.

$\mathrm{Al}$ conocer el pez con raro instinto la celada y peligros que le cercan, más espantado y rápido se agita para huir de aquel ruido que le aterra. seguro el cerco, ya el combate rudo y la corrida estrepitosa empieza. Erizadas de arpones las chalupas a los delfines rápidas se acercan y la lucha se traba, los aceros la carne dura del delfín penetran, y enfurecido el mónstruo se revuelve arrollando a su paso cuanto encuentra. Aquí formado en esquadrón embiste y muchas armas en su triunfo quiebra, allí de la embestida una chalupa perdiendo el equilibrio en el mar vuelca, y envueltos marineros y delfines en las aguas rodando se atropellan.

Aquí al dar un marino el arponazo con recio brio y redoblada fuerza ligero el pez se ha deslizado al golpe, y no encontrando el arma resistencia, el agresor cediendo al propio empuge cae abrazando el agua en su torpeza. otro allá más certero el hierro clava con fortuna mejor, mas tan violenta tan veloz es la huída,que arma y hombre adheridos al pez al fondo ruedan. Alguno haciendo alarde de prudente ata mañoso al arma recia cuerda dejando huir al pez con el acero, y detenerlo a su placer intenta; pero cuando el estremo osado y firme toda su fuerza en contenerlo emplea; avanza aquel y arrastra por trofeo al hombre por el agua en su carrera. Un diestro al dar el golpe bien seguro deja la lanza con la vara enhiesta clavada en el delfín, y encima pone un turbante morisco con presteza, y el pez huyendo con divisa turca reir hace a la alegre concurrencia. Otros palomas, cuervos y gaviotas con largas cintas dejan sujetas a las armas que clavan, y aunque oculto en las aguas el pez listo navega, su rumbo por el aire va marcando al ave a su pesar que inquieta vuela. Allá otro en un mónstruo cabalgado surca las aguas como una saeta, cual si fuera un centauro que surgiese de la mar en fantástica quimera 
ya se oculta en la líquida llanura, ya lejano aparece, corre, vuela; de nuevo se hunde, se alza en varios giros se revuelve, y el cetáceo en su firmeza despide de sus lomos el ginete que a nado busca presuroso tierra. Así en juegos diversos y vistosos pasan el tiempo mientras que en el mar mengua y convertido en un sangriento lago el sitio queda de tan rara pesca. Cuando el mar ha bajado, hacia la orilla, arrastran los cien peces que la llenan, pues hay alguno que a un robusto toro en peso y magnitud quizás le esceda. Allí contemplan muchos la figura del vivíparo pez con sus aletas, su fina dentadura duplicada, su lisa piel lustrosa y cenicienta. $\mathrm{Y}$ contentando los variados lances de cien suertes graciosas o grotescas a cual mas quedan todos satisfechos de tan alegre y divertida fiesta.

José Benito Amado.

1879.

Informe de la Sociedad Económica de Amigos del País de la Ciudad de Santiago sobre la conveniencia de poner remedio a los perjuicios ocasionados por los delfines en las rías de Arousa y Muros.

Informe de la Sociedad Económica de Amigos del Pais de la ciudad de Santiago, Gaceta de Galicia, 1879.

De la lectura del informe se deduce una confusión terminológica, pues se considera incorrectamente que el nombre en castellano del arroaz es el de marsopa, término que utilizan constantemente a lo largo del informe y especie que describen en detrimento del arroaz o delfín mular.

Informe a la sociedad económica de amigos del país de la ciudad de Santiago evacuado por la comisión de la misma sociedad, encargada de estudiar y proponer el medio más conducente a evitar los perjuicios que a la Industria salazonera ocasionan los delfines en las rías de Arosa y Muros.

La comisión nombrada por esta Sociedad Económica «para estudiar y proponer medio más conducente a evitar los inmensos perjuicios que a la Industria Salazonera proporcionan los Delfines, con su presencia continuada en las rías de Arosa y Muros» ha procurado examinar con la detención que requiere asunto de tan vital importancia y de sus investigaciones deduce: Que la causa principal del estado de abatimiento y decadencia de la Industria de Salazón en aquellas rías, donde en otro tiempo se manifestaba tan rica y pujante, consiste, sin duda, en la imposibilidad de pescar la Sardina por los destrozos que ocasiona en las redes del jeito, un cetáceo voraz, conocido vulgarmente en nuestras costas con el nombre de arroaz, y que es el terror de los pescadores en aquellas comarcas.

Este animal al que la ciencia llama Delphinus phocoena y en castellano es conocido comunmente con el nombre de marsopa, pertenece al órden de los Cetáceos, familia de los Delfinideos. 
El nombre vulgar de marsouin, con que es conocido en Francia, procede del latino maris-sus (cerdo marino) llamado así, ya por su mucha grasa, ya por la especie de ruido o gruñido que produce, siendo quizás por esta última razón por la que los portugueses y gallegos la denominan arroaz, que se deriva del nombre roaz que en portugués vale tanto como murmurador o gruñidor.

Difiere el marsopa del Delfin común en que su cuerpo es a proporción más grueso y su hocico menos agudo. Su tamaño es también diferente pues la longitud del marsopa rara vez pasa de metro y medio al paso que la del Delfín común se aproxima a tres metros; el número de dientes en el primero suele ser veintiuno y en el segundo llega a cuarenta $\mathrm{y}$ siete.

Esta Comisión no cree oportuno hacer una minuciosa descripción del marsopa, si bien juzga conveniente indicar algunas particularidades del mismo que, a su juicio, deben tenerse presentes al estudiar y escoger el medio más práctico de perseguirle.

Los marsopas se encuentran en todos los mares de Europa, lo mismo en el Occéano (sic) Atlántico que en el Mediterráneo, y entran en nuestras rías reunidos en numerosas manadas, siguiendo a la Sardina, y caminando a saltos sin sacar casi nunca a la superficie del agua más que la parte superior de su cuerpo, de modo que parece hacen en movimiento de rotación completo sobre sí mismos.

Suben los ríos cuando persiguen en carnizadamente al pescado, pero en general no pasan de la línea en donde acaba la mezcla de las aguas saladas con las dulces.

El instinto de estos animales es verdaderamente prodigioso; así parece darlo a entender su cerebro que es ancho, convexo y formado de númerosas y profundas circunvalaciones.

La gestación de la hembra dura diez meses, y paren uno o dos hijuelos a los que lacta con cuidado y protege constantemente mientras son débiles. El período de celo en los machos dura de Junio a Agosto, durante esta época en que se disputan con encarnizamiento las hembras, su pasión brutal los ofusca hasta el estremo de no hacer caso de peligro de ninguna clase; hay quien asegura que, como consecuecia de aquella excitación, sufren entonces una temporal ceguera.

La carne de los marsopas es dura y de un gusto poco delicado, la comen los habitantes de las costas del Norte, y por algunos se dice que en otra época tenía mucho consumo entre nosotros.

Su aceite es muy fino se parece al de la ballena y es muy apreciado en el comercio.

Por la utilidad que prestan estos animales, muchos pueblos, entre ellos los Islandeses, se dedican a su pesca que siempre ha sido accidental y bastante limitada, por ser de escaso tamaño y muy ágiles movimientos.

Estos son los detalles y cualidades culminantes de este cetáceo que, por los daños sin cuento que ocasionan en nuestras pintorescas rías, puede considerarse una verdadera plaga; como es la langosta en algunas provincias de España, y la Fhiloxera en los viñedos de Francia y Portugal.

Procede, pues, a juicio de esta comisión perseguir activamente a aquel destructor animal, y ahuyentarle a todo trance de las rías de Arosa y Muros, como único medio de evitar los perjuicios inmensos que ocasiona a su industria salazonera que constituye seguramente el principal elemento de riqueza en aquellas comarcas. 
Examinemos los distintos medios conocidos de perseguirles.

La manera más usada por otros pueblos de pescar y perseguir el marsopa, es, lanzarles un arpón o dardo, que generalmente tiene un fuerte mango al cual está atada una cuerda que el pescador va soltando a medida que el marsopa herido se aleja. Se ha observado que los demás vienen a saciarse en la sangre que sale con mucha abundancia de la herida de su compañero, al que no abandonan hasta que se lo han comido.

Este medio no lo cree aceptable la Comisión porque el poco volumen del cuerpo del marsopa y sus ágiles movimientos lo hacen muy difícil de arponar; y además con este sistema de persecución se obtendrían resultados tardíos, pero no inmediatos y efícaces como la gravedad del mal exige.

Los pescadores de Mont-Farville en Normandía se sirven para pescarles de redes de cuerda cuyas mallas tienen nueve pulgadas en cuadro y la red cerca de cinco o seis brazas de ancho y cuarenta o cincuenta de largo. Cuando los pescadores desde alta mar perciben marsopas en la costa, en los pequeños brazos o canales que forman las puntas de las rocas, amarran un cabo de las redes y con una chalupa las llevan a lo ancho formando una especie de circuito y atan el otro cabo a distinta roca; de suerte que cuando la mar se retira, se encuentran las marsopas encerrados en la red y quedan en seco.

Los islandeses que echan sus redes en la época de celo, pescan considerable cantidad de ellos debido a la excitación y aturdimiento en que entonces se hallan. Algunos han llegado a decir que si los islandeses cogían tan grande número de marsopas, consistía en que este animal por aquel tiempo se quedaba ciego por la formación de una pequeña membrana que le cubría el globo del ojo.

Este sistema de redes u otras parecidas pueden emplearse en nuestras rías, sobre todo en la de Arosa donde existen sitios muy apropósito para tenderlas, como en la entrada de la ría cerca de Sálvora, en la entrada de Rianjo, en la boca del río de Padrón y otros varios puntos.

Así, pues, esta Comisión cree oportuno llamar la atención de los fomentadores de Arosa para que individualmente o por medio de la asociación, se procuren redes de grandes mallas y distintos tamaños y conseguirán de esta suerte establecer, no sólo un medio permanente de perseguir aquel animal dañino; sino también una nueva industria que consistía en el aprovechamiento de sus ricas grasas, cuya producción superaría, a no dudarlo, a los gastos ocasionados por las redes. Comprendiéndolo así unos comerciantes de la indicada ría de Arosa, en el pasado siglo, propusieron al Gobierno fomentar esta pesca; según nos dice Cornide en su Ensayo sobre la Historia de los peces de las costas de Galicia.

Empero, este sistema de redes, como el de los arpones, tampoco puede aceptarse como principal medio de perseguir el marsopa en el momento presente, porque sus resultados lentos no responden a la necesidad inmediata que se siente de que desaparezcan en corto espacio de tiempo aquellos animales de las citadas rías so pena de ver completamente aniquilada su industria, y a sus pobladores sumidos en la más horrible miseria que, para librarse de ella, tendrían que acudir al triste recurso de la emigración.

Por todas estas razones creen los que sucriben que, para evitar estos males debe escogitarse un sistema de persecución, activa, continuada y de resultados inmediatos, y a su juicio esta sólo puede consistir en perseguirles a tiro con bala. En efecto, valiéndose de 
lanchas de vapor tripuladas por buenos tiradores que con armas de precisión y alcance pudieran perseguir de cerca los marsopas y lanzarles fuera de la ría se conseguiría, sin duda, el objeto que nos proponemos.

A obtener este buen resultado contribuiría seguramente el grande instinto con que se halla dotado este animal que, al verse perseguido sin tregua y perdida la calma y sosiego que tanto apetece, huiría despavorido de aquellos mares en busca de otros en que pudiera morar con más tranquilidad.

La experiencia parece también confirmar esta aseveración, toda vez que en un pequeño ensayo que se hizo hace dos años por los fomentadores de Arosa para perseguirles a tiro, se observaba que en el sitio donde se les había tirado no volvían a aparecer en mucho tiempo.

Cumple a esta Comisión manifestar que este medio que propone como más ventajoso para perseguir el marsopa, es el indicado por la casi totalidad de fomentadores, al contestar a la carta circular que se les ha dirigido para que se sirviesen informar sobre «el mejor medio de perseguir el delfín sin ahuyentar la sardina». Se les preguntaba, además, en aquel documento, si era necesaria la protección del Gobierno para poner en práctica el medio de persecución que se juzgase aceptable, a cuyo particular contestaron unánimes en sentido afirmativo, fundándose en el estado de abatimiento y miseria en que se hallaba el país, como consecuencia de las malas cosechas de estos últimos años.

Por todas las consideraciones anteriormente indicadas, se cree esta Comisión en el caso de proponer a fin de evitar los grandes daños que a la Industria de Salazón ocasionan los marsopas en las rías de Arosa y Muros, desterrarles de estas comarcas por medio de una persecución activa e incesante que debe hacerse con lanchas de vapor (tres para la ría de Arosa por ser más estensa que la de Muros y mayor a proporción el número de marsopas que la invaden, y una para la de Muros), tripuladas con hábiles tiradores que recorran las distintas ensenadas de estas rías, persiguiéndolos a tiro de bala hasta que consiga lanzarlos a la costa.

Estas lanchas de vapor no pueden costearlas el país por el estado precario en que se halla. Debe, pues, proporcionarlas el Gobierno; y pueden utilizarse para este objeto las que existen en los arsenales procedentes de fragatas desarmadas. Sus tripulantes o tiradores pueden ser marineros o soldados de la armada.

Los fomentadores facilitarán además, las embarcaciones tripuladas que sean necesarias.

Para conseguir del Gobierno de S.M. las lanchas de vapor y sus tripulantes se hace preciso que esta Sociedad Económica se dirija al Excmo. Sr. Ministro de Marina, por medio de la exposición razonada, para que a la mayor brevedad se sirva destinar a nuestras rías de Arosa y Muros, las cuatro lanchas de vapor con sus correspondientes tiradores.

Esto es lo que estima procedente esta Comisión que antes de terminar su cometido, se va a permitir hacer una escitación a esta Sociedad para que se sirva transmitirla a los fomentadores de nuestras rías, a fin de que procuren estudiar detenidamente las ventajas e inconvenientes de los distintos aparejos de pescar conocidos, como el boliche, la traíña, la almadrava (sic), etc., y de estas investigaciones deduzcan si será o no ventajoso el remplazo del jeito por alguna de aquellas redes, no sólo porque en estas sea menor el daño que ocasione el marsopa; sino también por la mayor cantidad de pescado que puedan aprisionar; y las mejores condiciones en que se haga la pesca de la sardina, cuya circunstancia 
puede influir de una manera notable en los precios, y en la mayor o menor facilidad de su venta en los mercados de consumo.

No obstante lo espuesto por esta Comisión, la Sociedad con su ilustrado criterio, acordará lo que estime más conveniente.

Santiago 29 de Junio de 1879. -José Antonio Parga y Sanjurjo. -Antonio Llamas. Vicente González. -Francisco Poch y Jover. -Juan Goday.

Aprobado por la Sociedad en sesión ordinaria celebrada el 28 de Junio de 1879. La exposición de que hace mención este dictámen se ha remitido al Excmo. Sr. Ministro Marina el 9 de Julio del mismo año.

EI VICE-SECRETARIO GENERAL,

José Vázquez Quirós.

1890.

Artículo de Juan Cuveiro Piñol describiendo las corridas de arroaces en Pontevedra.

CUVEIRO PIÑOL, Juan: «Unha corrida d'arroaces», A Monteira, $\mathrm{n}^{\circ}$ 25, 22 de marzo de 1890, pp. 193-194.

\section{UNHA CORRIDA D'ARROACES}

Ningún pode gabarse de ver n'a sua vida maís que solasmente unha vez esta clase de festa. Tampouco s'atopa en todal-as rías baixas nin en todo o litoral de Galicia, un sitio de mellor xeito q'a ría de Pontevedra, e n'esta ría á mesma Capital, por ter á cercustáncea de desfogar n'aquela ó rio Lerez.

Hay n'a devandita cividade, n'a mesma veira d'ela, un sitio que chaman «as Corbaceiras», onde n'o tempo de que vou falar, había unha barca pra pasa la xente e mai lo gando a parroquia de Poyo: Pois ben, n'este barrio da Moureira onde viven os pescadores e xente probe, non falta quen garda unha rede feita de cordas d'esparto, pro grosas é fortes, e anque cando hay qu'usala, arromendase e repárase polos desprefeutos que sole ter, e que costa bos cartos, esta rede esténdese dend'o muelle das Corbaceiras hastra á veira de Poyo n-a orela d'o mar, de sorte que quedan dentro, rio arriba, todo los arrôaces que co'a rubida d'a marea, soben ô rio, no que se folgan os peixes hastr'a debalada da dita marea, e enton, é cando comeza a festa, que ben merece unha discriución.

Os animaes cando baixan do rio e alcontranse encerrados e ven que se lles vai acabando a auga do mar, comezan a dar unhas carreiras que se asemellan á voaduras, unhas veces emparellados e outras sôos; volvense tolos, é algún d'eles querse choutar â terra. Os homes e os rapaces, cando xa non queda d'auga mais q'a do rio, bótanse a él, póndose acabalo dos peixes, que c'o a mesma coraxe que teñen lévanos unha grande distancia sin cairse; outros tiranlles arpons, pedras é hastra tiros, de sorte que aquelo convírtese nunha festa d'un genero novo, d'a que non quedan pouco ademirados hastra os mesmos estrangeiros. Outras

Cuadernos de Estudios Gallegos, Tomo LI, Fascículo 117, Santiago 2004. (Págs. 313 - 362) 
veces arremoíñanse en runfladas os arrôaces e acometen a rede, tal é o instinto que teñen, pro como está pol a parte de fora arrodeada de lanchas é botes, desd' elas con remos é paus, fan recuar ôs animaes, que xa fatigosos e cheos de firidas e pancadas, deixanse coller hastra dos nenos, e traenos â terra onde os poñen en toradas pra estraelles a graxa, que por certo e das mais finas, e co importe d'ela cobren os gastos da compostura da rede, e os das lanchas é botes.

O arrõaz e un peíxe moi tímedo, õ revés d'o que nos parés cando os vemos andarõ á reboladas por detrás d'a Maestranza n'o mar d'a Cruña, asemellándose á porcos; os pescadores rabean co-eles porque lles rachan as redes, pois son tan vuraces que nunca se ven fartos e andan de veces detrás d'os barcos algunhas legoas, non porque queiran õ home, como se lles figuraba ôs griegos, senon por comer os peixiños, que tamen van detras do:'os barcos pra aproveitar os despirdicios d' eles; pol-o demais son tamen muy amantes d'a familia, e en proba d'elo contarei o que vin estando n-os baños d'a illa d'a Toja ou Loujo, qu' é o mesmo.

N-unha pena ou con, qu' está n'a veira d'o mar n-a dita illa, hay unha raxadura d'unhos dous metros de profondade, moy estreita qu' apenas colle un peixe da grandura d'un arroaz. Estaba eu contemplándoa desd' a orela da illa, cando vin vir unha ruflada d'aqueles peixes, que todo se lles volvía ir e vir â tal raxadura, mentres durou a marea que cobría ó con; chamóume a atincion aquel cotío ir e vir dos animaes: agardei hastra que debalase ó mar, e cando me acerquei â pena, vin, co'a suspresa mais grande, qu' habia alí un arrôaciño qu' inda estaba coleteando drento da raxadura, pro sin poder erguerse pra ningun lado: o probe animal entrara nela, pro non poido sair, e os outros arrôaces que ían alí tantas veces quizaes con mentres de ausiliar ô seu compañeiro ou fillo d'un déles, tiveron que volverse sen poder consiguilo.

En Pontevedra e donde lle chaman arrôaz; n'a Cruña golfin; pertenece a familia delphinus; tense por vivíparo é non ovíparo com' outros peixes.

JUAN CUVEIRO PIÑOL

Valladolid, Febreiro de 1890.

1923, julio, 4.

Artículo de prensa de Ángel Bernárdez sobre la necesidad de poner remedio al problema pesquero con los delfines.

BERNÁRDEZ, A.: «Los problemas de la pesca», Faro de Vigo, 4-7-1923, p.1.

Los cetáceos dañinos

Ha cundido en muchos de nuestros puertos la idea de hacer una campaña colectiva para conseguir que los poderes públicos adopten medidas encaminadas al exterminio de los cetáceos que ahuyentan la pesca.

Cuadernos de Estudios Gallegos, Tomo LI, Fascículo 117, Santiago 2004. (Págs. 313 - 362) 
En el Ministerio de Marina, según en otra comisión hemos expuesto en las columnas de FARO DE VIGO, existen informes contradictorios acerca de este problema, sin duda debidos a que en las costas españolas sa da un mismo nombre a distintas variantes de aquella clase de animales. Para que esta situación no continúe por más tiempo, se van a aunar todos los esfuerzos de los elementos directamente interesados con objeto de que sea enviada a estas costas con toda urgencia una comisión científica a fin de que estudie y resuelva este interesante asunto.

Con tal motivo se dirigirán estos días numerosos telegramas al ministro de Marina, inspirados muchos de ellos por los mismos pescadores que están viendo como, el gran banco de sardinas que arribó hace pocos días a estas costas y, que al parecer aún subsisteen ellas aunque profundizándose durante el día, es objeto de la persecución de los arroaces que en número infinito infestan las aguas.

Ángel Bernárdez.

1923, julio, 4.

Artículo de prensa de Ángel Bernárdez sobre la necesidad de poner remedio al problema pesquero con los delfines.

BERNÁRDEZ, A.: «La pesca en Vigo», La Voz de Galicia, 4-7-1923, p.1.

\section{LA PRESENCIA DE «ARROACES» AHUYENTA LA SARDINA}

Hoy estuvieron en Vigo comisiones de pescadores de diversos puertos para pedir a las autoridades que expongan al Gobierno su deseo de que envíe a las costas gallegas una comisión científica que se encargue de estudiar cuáles son los cetáceos cuya presencia ahuyenta la pesca, para procurar su exterminio.

Los pescadores creen que los «arroaces» hacen emigrar la sardina de estas rías y como en el Ministerio de Marina tienen datos respecto a este asunto que se contradicen, desean que este punto tan importante quede aclarado, pues la falta de sardina tiene en la miseria a multitud de familias.

Cuentan los pescadores que han visto estos días a varios «arroaces» de enorme tamaño perseguir ferozmente a un banco de sardina que había llegado a estas aguas.

El banco de sardina continúa aún en las cercanías de Vigo, pero comienza a alejarse huyendo de los infinitos «arroaces» que infestan esta costa. -Bernárdez. 
1923, julio, 18.

Artículo de prensa de Ángel Bernárdez sobre la comisión técnica encargada de estudiar y proponer en la ría de Vigo soluciones para resolver el problema pesquero con los delfines.

BERNÁRDEZ, A.: «La pesca en Galicia», La Voz de Galicia, 18-7-1923, p. 1.

Una información interesante

Desde ayer se halla en Vigo la comisión enviada a Galicia por el Ministerio de Marina, accediendo a los ruegos que le dirigieron las sociedades marineras de diversos puertos, para realizar una información sobre la conveniencia de perseguir a los arroaces por ser dañinos para la pesca. Componen dicha comisión el capitán de corbeta, con cargo en la Dirección general de Navegación y Pesca, D. José María Lleó; el doctor en Ciencias, señor Alaejos, y el auxiliar del Instituto Oceanográfico, D. Benigno Rodríguez.

La idea del exterminio de los cetáceos peligrosos para la gente que vive de la industria extractiva del mar, no sólo porque ahuyentan la pesca, sino también porque destruyen los aparejos, es muy antigua en Galicia. Hace medio siglo, abogaron por ella, reunidos en asamblea en Villagarcía, todos los fomentadores y patrones de embarcaciones de la Ría de Arosa y otros puertos cercanos, quienes acordaron solicitar del Gobierno que dotase a los pescadores de fusiles lanzaarpones, para tal objeto, petición que dicho sea de paso, no fue atendida, sin que tampoco se hiciese cosa alguna para mitigar los perjuicios de que los navegantes se quejaban, ni menos para estudiar otra forma de evitarlos.

De aquella fecha para acá, muchísimas veces los marineros gallegos renovaron sus reclamaciones y siempre con el mismo negativo resultado. Una de las más recientes la formuló en agosto del año pasado la Asociación General de Industrias Pesqueras de Galicia, la que, dando al Ministerio de Marina todas las facilidades posibles para que la atendiese, le ofreció uno o dos vapores para que, tripulados por marineros de la Armada, se emprendiese una activa persecución contra los cetáceos conocidos indistintamente en las costas de España con los nombres de arroaces, toninas, marsopas y delfines, aunque entre ellos existan algunas diferencias.

Aceptada en un principio la proposición, pronto se supo que la Dirección General de Navegación y Pesca no podía por el momento conceder lo que se solicitaba, por oponerse a ello varias disposiciones y Reales órdenes publicadas desde el año 1905, en que se celebró en Madrid una asamblea de industrias de la pesca, con motivo del famoso pleito del xeito y la traíña, en la que, entre otras conclusiones, se acordó que los mencionados cetáceos, lejos de ser perjudiciales para la pesca, son los auxiliares de los pescadores, toda vez que agrupan la sardina en grandes masas y facilitan su captura. Tan a rajatabla se prestó cumplimiento de ese acuerdo que, según me ha informado un vocal de la Junta de Navegación y Pesca, fue prevenida la Diputación Provincial de Barcelona para que suspendiese la 
adjudicación de premios en metálico que había ofrecido a quienes apresasen ejemplares de dichos cetáceos.

Nuevamente quedó paralizado este asunto hasta que hace quince días, según oportunamente comuniqué a los lectores de LA VOZ DE GALICIA, los pescadores de varios puertos solicitaron del ministro de Marina el urgente envío de una comisión científica con el encargo de estudiar el problema para resolverlo definitivamente.

La comisión está ya en Galicia, como queda dicho, y se propone realizar una información detenida, recogiendo todas cuantas opiniones se le comuniquen, de palabra o por escrito, para después ella informar a su vez y proponer lo que estime procedente.

La tarea no ha de ser muy fácil, pues aunque no surjan contradicciones tan grandes como la existente entre lo acordado en la Asamblea de 1905 y lo que desean los marineros gallegos, no faltarán algunas tan raras como las que el autor de estas líneas tuvo ocasión de notar estos días, oyendo decir a algunos pescadores de Cangas que los mismo cetáceos que en las rías gallegas les destruyen las redes no les causan este perjuicio en las costas de Portugal. Puede ocurrir que esto sea obra de la casualidad, como acaso lo sea también el hecho de creer en unas partes de las costas españolas que los arroaces agrupan a las sardinas y en otras que las ahuyentan. Lo natural es que las sardinas huyan en sentido opuesto al que las atacan sus enemigos, y si éstos vienen de la parte del mar, huirán aquéllas hacia tierra arremolinándose y facilitando su captura a los pescadores; mientras que si la agresión es por la parte de la costa, escaparán los mansíos dispersándose mar adentro y poniéndose a cada momento a mayor distancia de los barcos pesqueros.

Una versión más aceptable es que alguna clase de los delfínidos no es más audaz que las otras y no repara en lanzarse contra la red, aunque la vea, y la atraviese, destrozándola, cuando se lanza sobre las sardinas para devorarlas; mientras que otras variantes de la misma son más tímidas y se retiran al divisar las redes, del mismo modo que hay unos peces que al sentirse presos en el anzuelo se debaten con energía tratando de escapar, mientras que otros, acaso más corpulentos, se entregan desde el primer momento dejándose conducir sin resistencia desde el fondo del mar hasta flor de agua. Lo que no ofrece duda es que existen cetáceos dañinos para la pesca de la sardina; y si no bastasen para demostrarlo las constantes reclamaciones de los marineros gallegos, podría agregarse a ellas el ejemplo de lo que ocurre en Francia, donde los buques guardapescas prestan el más estricto auxilio a los pescadores de sardinas, tan pronto comienza la costera, en las luchas contra aquella clase de enemigos.

Vigo.

ÁNGEL BERNÁRDEZ. 
1924, noviembre, 23.

Artículo de prensa sobre el problema pesquero con los delfines en las Rías Baixas.

ANÓNIMO: «Las sardinas y los delfines», La Voz de Galicia, p. 1.

La sardina y los delfines

Nuestro estimado colega el «Faro de Vigo», publica un interesante artículo del que recogemos algunos párrafos, que van a continuación:

«Según noticias que nos suministran elementos pesqueros, estos días existe una abundancia enorme de sardinas en estas costas.

Nos aseguran aquellos elementos, que el banco llega desde Finisterre hasta el cabo Estay, en nuestra bahía, y es tan espeso, que hay sitios en donde parece que hierve el mar, según la frase de los pescadores.

Esta noticia sería completamente satisfactoria, sobre todo aquí, donde casi todo está ligado con la industria de la pesca, si al mismo tiempo que la sardina, o mejor aún, atraído por la presencia de ella, no se observase la estancia en nuestras aguas de un número considerabilísimo de delfines, que causan daños incalculables.

En tal forma es dañina la presencia de los «arroaces» entre la sardina, que los pescadores se ven casi imposibilitados de largar los aparejos, pues aquellos cetáceos se los destrozan materialmente, al ir en busca del sabroso pez.

Hasta tal punto es esto ciertísimo, que anteayer, un vapor que largó el aparejo, tuvo que recogerlo rápidamente, pero no sin que los delfines le hubieran hecho en la red unos quinientos agujeros.

Y como además de la pérdida que esto supone hay que añadir que por los agujeros que hacen en el aparejo los «arroaces» se marchó la pesca que ya había sido capturada, es por lo que decimos que los pescadores se ven casi en la imposibilidad de largar las artes, ya que ello representa un perjuicio cierto sin resultado práctico alguno.

Ahora bien, hace tres años estuvo en Vigo una comisión técnica encargada de hacer estudios relacionados precisamente, con los delfines y con la manera de librar de este peligro a los pescadores.

Y parece que la conclusión de los estudios, o una de las conclusiones, fue la posibilidad de acabar con los arroaces persiguiéndolos con ametralladoras. Y se recordaba, a ese respecto, que en Francia se empleó hace bastantes años el mismo procedimiento, y los arroaces, muertos unos y ahuyentados otros, dejaron de ser la pesadilla de los pescadores y el mayor enemigo de su industria.

Los cuantísimos intereses ligados con la industria de la pesca y la importancia que esta industria tiene para la economía nacional, muévennos a solicitar de los Poderes públicos una rápida acción en el sentido indicado; esto es, una campaña de verdadera persecución de los delfines, por medio de ametralladoras, hecha por los cañoneros de la Armada nacional».

Nos parece justa la pretensión y a ella nos atenemos, pues en estos tiempos de crisis de la industria pesquera deben intentarse todos los esfuerzos para favorecer y fomentar la arribazón de sardina a nuestras costas. 
1956, noviembre, 8 .

Informe de Santiago Brugarolas Canals remitido a Industria Ballenera Sociedad Anónima (IBSA) proponiendo la industrialización del delfín.

Archivo del autor, Caja clientes A-Z (1951-59), carpeta Brugarolas.

8 Noviembre 1956.

Industria Ballenera, S.A.

La Coruña.

Muy Sres. míos:

Recibí su atta. carta del 30 de Octubre ppdo., que paso a corresponder con la atención que merece.

Contando con el interés que para Vds. podía tener el estudio que hace tiempo me preocupa, creí conveniente ofrecerlo a Vds. aunque he de aclarar previamente que no se trata de ningún invento, sino de cómo aprovechar hasta el máximo todos los elementos de que disponen Vds.

Mi pregunta sobre condiciones, se limitaba a poder conocer si en algo podía ser correspondida esa colaboración mía. Dejo ese asunto a su caballerosidad, para no sentar en principio dudas que no conducirían a nada práctico. Expuesto todo esto, pasaré a plantear mis proyectos que yo no puedo explotar para no crear un nuevo negocio paralelo a los míos, que sobre todo en los momentos actuales, necesitan la mayor atención.

Teniendo en cuenta las dificultades que presenta la captura de la ballena y cachalote por largos viajes; determinados requisitos nacionales e internacionales; la inseguridad de la pesca, siempre temporal y los períodos de inactividad; urgencia de tratamiento para evitar su putrefacción, etc., me preocupé de buscar otros animales marinos que pudiendo dar buenos aceites de utilidad industrial, simplificaran o hasta cierto punto anularán los problemas que presenta la pesca de la ballena. Esto puede resolverse, dedicándose durante las temporadas de paro o de una manera permanente, a la pesca del delfín vulgar. Este pez abunda especialmente en el sur del Mediterráneo, Atlántico, Cantábrico y en la amplia zona meridional marítima de todo el mundo. Es mamífero como la ballena y su aceite es también bastante parecido al de aquella, como verán en hoja a parte. En anterior ocasión pude apreciar la calidad del aceite de delfín, por una muestra que me remitieron desde Turquía, con la que pude conocer bien ese producto.

Es un pez carnívoro, que se encuentra desde muy cerca de la playa; los he visto aparecer a centenares entre Algeciras-Málaga. Tiene un peso promedio de unos 35 kilos y de 1 a 1'5 metros de largo, lo que representa técnicamente una serie de ventajas, pues facilita extraordinariamente su pesca y su explotación industrial. Esa tan posible rapidez de tratamiento, beneficia de manera considerable la calidad de la carne, del aceite y de la harina que de esos peces pueden obtenerse. 
Estuve en contacto con el capitán de un vapor canario que me contó que, entre el estrecho de Gibraltar y Almeria acostumbraban pescar algún delfín cuya carne (filetes) comían a bordo y la encontraban muy buena. Aquel Sr. me expuso que, la carne de delfín que no podía comerse fresca, era suceptible (sic) de ser salada para otras ocasiones, algo así como los filetes de bacalao que se venden en cajas y que Vds. ya conocen.

El olor del aceite de delfín, si se trabaja en tiempo oportuno, es tan fino como el de ballena; su color es amarillo-limón-oro, suceptible (sic) de blanquear y de baja acidez. El aceite obtenido de los residuos, es rojo-rubí. De la cabeza, hígado y pulmones, se obtienen aceites de mejor calidad.

Prensada la carne y residuos debidamente, bajo los sistemas conocidos, se puede conseguir una grasa por expresión y, en la prensa una harina de calidad. La parte de residuos, practicamente inútil, puede servir como abono.

En realidad, sólo hay como pérdida la parte de agua, que se calcula en $10 \mathrm{p} \%$ la contenida en el cuerpo pero para no sufrir errores, lo consideraré como $15 \mathrm{p} \%$. Por lo tanto, si por cada $100 \mathrm{kgs}$. pescados se aprovechan $85 \mathrm{kgs}$. y el precio medio de venta fuese neto de 8 '- pts. el aceite y 6'- pts. la harina (que mi hermano para su granja y procedente de Canarias la paga a 9'- pts.), resultaría por venta -en cifras redondas- 600 '-pts. $(85 \times 7)$ con las que habría de atender los gastos y beneficios. Partiendo de un peso medio por delfín de $40 \mathrm{kgs}$. el valor de venta (cuyos precios unitarios son bajos para poder prevenir cualquier gasto ahora imprevisible) sería de unas 235 pts. por animal pescado $(40$ x $15=6.40-6 \mathrm{x}$ $7=238$ ).

Tengo el íntimo convencimiento que este asunto en manos de Vds. es magnífico. No solamente pondría la factoría de Vds. en constante actividad con la consiguiente reducción de gastos generales y un considerable aumento en la cifra de venta, sino que se ahorrarían muchas divisas que todavía deben invertirse para importar aceites de pescado. Finalmente he de remarcar que para pescar delfines, no son menester viajes largos, ni buques de tonelaje ni tripulaciones numerosas; todo eso quedaría reducido a un mínimo.

Dejo ahora a la consideración de Vds. cuanto dejo expuesto y celebraré que el estudio por su parte, les lleve a considerar la importancia que esto tiene y que nadie ha explotado todavía, por lo menos de una manera adecuada a lo que esta cuestión necesita.

Queda nuevamente en la espera de sus gratas noticias, suyo atto. y s.s.

\section{Santiago Brugarolas (rúb.)}

DELFÍN, cetáceo carnívoro; los hay hasta 3 metros de largo, con una abertura nasal encima de los hojos, por la que puede arrojar con fuerza el agua que traga.

Los animales incluidos en este género «Delphinus Cuv.» se caracterizan por las mandíbulas prolongadas bruscamente en forma de pico, formando con la frente un ángulo generalmente muy marcado y provistas las dos de numerosos dientes cónicos y la aleta dorsal bien desarrollada. Las especies más conocidas, son:

D. delphis ${ }^{69} \mathrm{~L}$., de 2 a 2'5 m. longitud, con el hocico medianamente largo y separada de la frente, las dos mandíbulas de igual longitud con 25 a 50 dientes. Se encuentran en el

\footnotetext{
${ }^{69}$ Se trata del delfín común o delphinus delphis.
} 
hemisferio Norte. Vive reunido en bandas de 8, 10 o más individuos. Se alimenta de peces y algunos crustáceos. Generalmente, sigue a los buques por si algo puede aprovechar de los residuos del mismo. Uno de los medios más usados para capturarlos, consiste en ahuyentarlos hacia la playa, hasta que varan en ella.

D. Tursto ${ }^{70}$ Fabr. de 3 a 4,5 m. longitud, con la mandíbula inferior más larga que la superior, con 42 a 48 dientes cada una; dorso negro pardo negruzco, vientre blanco. También vive en bandadas. Se encuentra en el Atlántico.

D. rostratus de unos 2'5 m., con el ángulo formado por el hocico y la frente no tan pronunciado como en las demás especies. 44 a 52 dientes por mandíbula. Dorso negro y el vientre blanco rojizo. Vive también en el Atlántico y Meditarráneo, en bandadas.

ACEITE DE DELFÍN. Líquido de color amarillo, de olor a pescado y algo a cuero, bastante soluble en alcohol. Por enfriamiento, deposita palmitato cetílico (parecido al cachalote). Contiene triglicérido del ácido valeriánico y de 2 a 20 p $\%$ de insaponificable. El aceite de todo el cuerpo, presente:

Densidad a $15^{\circ}$ C. $0,925-0^{\prime} 936$

Índice de yodo . . . . 8 80 a 120

Los aceites de cabeza y barba tienen la composición siguiente: Ácidos no saturados: $\mathrm{C}_{14}$, 3-5- $\mathrm{p} \%$ (2 átomos yodo); $\mathrm{C}_{16}$, 20-27, (2 átomos yodo); $\mathrm{C}_{14}$ (oleico y algo linólico); $\mathrm{C}_{20}, 5-10$ (5-6 átomos yodo); $\mathrm{C}_{22} 2-7 \%$ (5-6 átomos yodos). Ácidos saturados: isovaleriánico, $14-25 \%$; láurico, 3-5\%; mirístico, 12-25\%; palmítico, 4-7\% (la presencia de ácido esteárico es dudosa)

\begin{tabular}{|c|c|}
\hline ANÁLISIS COMPARATIV & 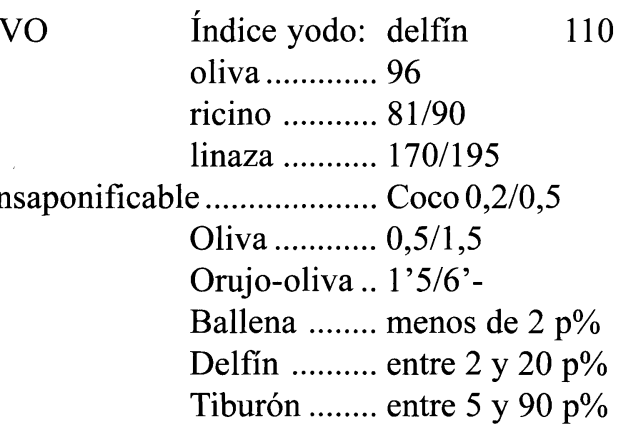 \\
\hline
\end{tabular}

ALCOHOLES NATURALES: El alcohol mirítico, se encuentra en los aceites de ballena y delfín. El alcohol cetílico, se encuentra en el aceite de esperma de ballena y en menor proporción en los aceites de delfín. En los aceites de esperma de ballena y de delfín, se encuentra el alcohol oleico en estado libre y en forma de éster de una pequeña parte de los ácidos grasos.

\footnotetext{
${ }^{70}$ Se refiere al arroaz o delfín mular, actualmente Tursiops truncatus y, anteriormente denominado por Fabricius Delphinus tursio.
} 


\section{ANÁLISIS SEGÚN MARTINENGHI:}

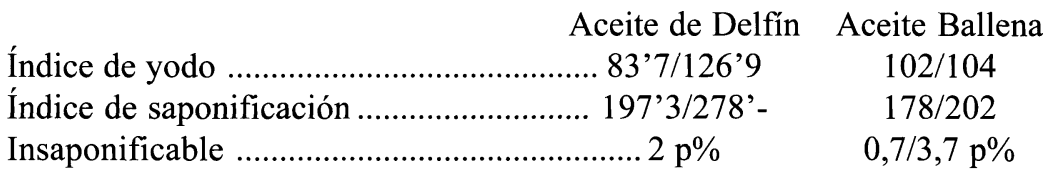

OTRA INFORMACIÓN. Los delfines se pescan en el Cabo Hatheras y cabo Cod. La mayor parte de la carne fresca es consumida y la demás no consumida, se sala y es exportada. Tiene mucha importancia el aceite que se obtiene, separando el obtenido del cuerpo del cuerpo $(s i c)$ del de la quijada, que tiene más valor.

Los aceites de delfines se caracterizan por su extraordinaria alta calidad de glicéridos de volátiles acidos grasos que contienen.

8 Noviembre 1956.

\section{BIBLIOGRAFÍA}

ÁNONIMO. «Nuestra riqueza pesquera», Faro de Vigo, 18-7-1923, p. 1

ANÓNIMO. «La sardina y los delfines», La Voz de Galicia, 23-11-1924, p. 1.

ANÓNIMO. «La aviación coopera a la destrucción de cetáceos», Boletín de Pescas, Instituto Español de Oceanografía, no 119, julio 1926, pp. 203-204.

ANÓNIMO. «Persecución de arroaces», Boletín de Pescas, Instituto Español de Oceanografía, $\mathrm{n}^{\circ}$ 129, mayo 1927, p. 154.

ANÓNIMO. «Sucesos acaecidos sobre la pesca de la sardina desde el establecimiento de jávegas en Galicia, y reflexiones sobre este fruto y modos de cogerlo», Pesquerías Tradicionales y conflictos ecológicos (1681-1794), Ministerio de Agricultura, Pesca y Alimentación, Madrid, 1991, pp. 285-290.

AGUIRRE FANIQUE, L. de. «España vuelve por sus fueros balleneros», Información comercial española, Madrid, 1952, pp. 336-342.

BERNÁRDEZ, Á. «Los problemas de la pesca», Faro de Vigo, 4-7-1923, p.1.

- «La pesca en Vigo», La Voz de Galicia, 4-7-1923, p.1.

- «La pesca en Galicia. Una información interesante», La Voz de Galicia, 18-7-1923, p. 1.

BUSTO, M. «Pudiera no ser fabuloso el pleito de los delfines. Esta basado en un hecho real y verdadero», Boletin del Instituto de Estudios Asturianos, $\mathrm{n}^{\circ}$ 102, Oviedo, 1981.

CABRERA, Á. Fauna Ibérica. Mamiferos, Madrid, 1914.

CAWARDINE, M. et al. Ballenas, delfines y marsopas, Omega, Barcelona, 1999.

CORNIDE SAAVEDRA, J. Ensayo de una historia de los peces y otras producciones marinas de la costa de Galicia, Edicións do Castro, 1983 (1787).

COUSTEAU, J.Y. Los secretos del mar, n 32, Ediciones Folio S.A., 1994, pp. 72-86. 
CUVEIRO PIÑOL, J. «Unha corrida d' arroaces», A Monteira, año II, nº 25, 22 marzo de 1890.

FERREIRA PRIEGUE, E. Galicia en el comercio maritimo medieval, Fundación Barrié de la Maza, A Coruña, 1988.

- "O desenvolvemento da actividade pesqueira desde a alta idade media ó século XVII», Historia da pesca en Galicia, USC, Santiago de Compostela, 1998.

FILGUEIRA VALVERDE, X. y FORTES ALÉN, M. X. Fr. Martín Sarmiento. Epistolario, Consello da Cultura Galega, Santiago de Compostela, 1995.

GARCÍA TATO, I. y VALDÉS HANSEN, F. (ed.). Vida y obra del Reverendo Padre Maestro Fray Martín Sarmiento (1695-1772), CSIC-Xunta de Galicia, Santiago de Compostela, 2003.

HOYO, J. del: Memorias del arzobispado de Santiago, Santiago de Compostela, 1950 (1607). La Perseverancia, año I, $\mathrm{n}^{\circ}$ 46, 13 agosto 1859; $\mathrm{n}^{\circ}$ 47, 18 agosto 1859.

LANDÍN TOBIO, P. De mi viejo carnet. Crónicas retrospectivas de Pontevedra y su provincia, Pontevedra, 1949, pp. 111-115.

LÓPEZ FERREIRO, A. Fueros municipales de Santiago y su tierra, 1975 (1875).

LORENZO FERNÁNDEZ, X. O mar e os rios, Galaxia, 1982, pp. 120-121.

- Historia de Galicia (dirigida por Ramón Otero Pedrayo), volúmen II, Akal, 1979, pp. 412-413.

PARGA SANJURJO, J.A. et al. Informe a la Sociedad Económica de Amigos del País de la Ciudad de Santiago evacuado por la comisión de la misma Sociedad, encargada de estudiar y proponer el medio más conducente a evitar los perjuicios que a la Industria de la salazonera ocasionan los Delfines en las rías de Arosa y Muros, Gaceta de Galicia, Santiago de Compostela, 1879.

RODRÍGUEZ SANTAMARÍA, B. Diccionario ilustrado, descriptivo, valorado, numérico y estadístico de los artes, aparejos e instrumentos que se usan para la pesca maritima en las costas del Norte y Noroeste de España, Madrid, 1996 (1911).

- Diccionario de las artes de pesca de España y sus posesiones, Madrid, 1923.

SAÑEZ REGUART, A. Diccionario histórico de los artes de la pesca nacional, Ministerio de Agricultura, pesca y alimentación, Madrid, 1988 (1792).

SARMIENTO, M. «De los atúnes y de sus transmigraciones y conjeturas sobre la decadencia de las almadrabas; y sobre los medios para restaurarlas», Pesquerias Tradicionales y conflictos ecológicos (1681-1794), Ministerio de Agricultura, Pesca y Alimentación, Madrid, 1991, pp. 61-99.

VV.AA. Ballenas, delfines y marsopas, Plaza \& Janes-Tusquets, Barcelona, 1991,

VILLENA, E. de: Arte Cisoria, Editorial Humanitas, Barcelona, 1984.

\section{ARCHIVOS CONSULTADOS}

Archivo del Museo de Pontevedra, prensa antigua.

Archivo del autor.

Archivo General de Marina Álvaro de Bazán (Viso del Marqués, Ciudad Real), Fondo documental de Ferrol, leg. 14.412.

Cuadernos de Estudios Gallegos, Tomo LI, Fascículo 117, Santiago 2004. (Págs. 313 - 362) 